\title{
Graphene impregnated electrospun nanofiber sensing materials: a comprehensive overview on bridging laboratory set-up to industry
}

\author{
Adel Mohammed Al-Dhahebi ${ }^{1,2}$, Subash Chandra Bose Gopinath ${ }^{3,4}$ \\ and Mohamed Shuaib Mohamed Saheed ${ }^{2,5^{*}}$ (B)
}

\begin{abstract}
Owing to the unique structural characteristics as well as outstanding physio-chemical and electrical properties, graphene enables significant enhancement with the performance of electrospun nanofibers, leading to the generation of promising applications in electrospun-mediated sensor technologies. Electrospinning is a simple, cost-effective, and versatile technique relying on electrostatic repulsion between the surface charges to continuously synthesize various scalable assemblies from a wide array of raw materials with diameters down to few nanometers. Recently, electrospun nanocomposites have emerged as promising substrates with a great potential for constructing nanoscale biosensors due to their exceptional functional characteristics such as complex pore structures, high surface area, high catalytic and electron transfer, controllable surface conformation and modification, superior electric conductivity and unique mat structure. This review comprehends graphene-based nanomaterials (GNMs) (graphene, graphene oxide $(\mathrm{GO})$, reduced $\mathrm{GO}$ and graphene quantum dots) impregnated electrospun polymer composites for the electro-device developments, which bridges the laboratory set-up to the industry. Different techniques in the base polymers (preprocessing methods) and surface modification methods (post-processing methods) to impregnate GNMs within electrospun polymer nanofibers are critically discussed. The performance and the usage as the electrochemical biosensors for the detection of wide range analytes are further elaborated. This overview catches a great interest and inspires various new opportunities across a wide range of disciplines and designs of miniaturized point-of-care devices.
\end{abstract}

Keywords: Electrospinning, Electrospun nanofibers, Nanocomposites, Graphene, Graphene oxide, Reduced graphene oxide, Graphene quantum dots, Electrochemical biosensors

\section{Introduction}

Recently, the demands for highly sensitive, selective, and low detection limit biosensors to detect the low abundance of analyte molecules have increased substantially not only in biomedical applications but also in food industries, agriculture and environmental monitoring

\footnotetext{
*Correspondence: shuaib.saheed@utp.edu.my

${ }^{2}$ Centre of Innovative Nanostructure \& Nanodevices (COINN), Universiti Teknologi PETRONAS, 32610 Seri Iskandar, Perak Darul Ridzuan, Malaysia Full list of author information is available at the end of the article
}

[1]. The development of ultrasensitive devices and new detection approaches for the efficient point-of-care testing with low-cost and high accuracy is an urgent need in the healthcare industry. Biosensors have received tremendous attention as an alternative to the conventional analytical methods due to the unparalleled specificity, sensitivity, rapidity of analysis and the ability to provide a long-term monitoring and a wide range of detection capabilities, including glucose, blood oxygen level, antibodies, mycotoxins, heavy metals in drinking water, pesticides, nucleic acid and body motions pesticides [2]. 
A variety of approaches have been exploited, including electrochemical biosensors [3-5], fluorescent biosensors [6], colorimetric biosensors [7, 8], potentiometric biosensors [9, 10], optical biosensors [11], and Raman spectroscopy-based platforms [12, 13]. Compared with other detection methods, electrochemistry biosensing platforms provide a more facile, cost-effective and a highly sensitive detection method which enables the fast response-recovery times, monitoring different analytes, and a very low detection limit [14-16]. Recent efforts have focused on improving the sensing features of electrochemical biosensors by increasing the specific surface area of the transducers (interacting materials with the target analyte), where the larger the surface area of the sensing materials, the higher their ability to interact with the medium (analytes) [2].

In recent years, nanocomposite transducers comprising nano-sized materials and polymer matrices have captivated immense attention in the field of advanced materials science due to their remarkably improved thermal, chemical and dimensional stabilities, applicability, electrical conductivity, mechanical and functional properties that can be achieved at relatively lower filler loading [17]. The improved properties are mainly attributed to a very high aspect ratio (in the range of 100-1000) of nano sized fillers, yielding light-weight composites with alterable multifunctional properties which makes them potential candidates for several advanced applications including diagnostics and repair human tissues [18, 19], aid in cellular growth and proliferation [18], detection of pathogens and heavy metals and offer unparalleled platforms for electrochemical biosensing. In particular, nanocomposites made of graphene based nanomaterials (GNMs) with polymers and or nanoparticles such as metals, carbon nanotubes (CNTs), quantum dots, etc., could provide abundant opportunities for fabricating novel sensors and biosensors with enhanced performance [17, 20, 21].

GNMs including graphene, graphene oxide (GO), reduced graphene oxide (rGO) and graphene quantum dots (GQD) have attracted extensive interest in research/industrial applications because of their potential and unique properties. GNMs are suitable for fabricating a wide range of novel biosensors with improved functionalities and analytical capacities thus providing fascinating opportunities for point-of-care detection, lab-on-chip devices, wearable and flexible electronics, foodborne detection, and environmental monitoring [2, $22,23]$. The attractiveness of GNMs transducers relies not only on their ability to act as efficient and stabilizing platforms for the biorecognition elements, but also on their large surface area, small size, physio-chemical properties, high reactivity, high catalytic efficiency, strong adsorption ability, controlled morphology and structure, biocompatibility, and electrocatalytic properties $[18,24]$. The favourable structural and compositional synergy of GNMs allows them to be excellent electrode materials for fabricating various sensing platforms [1]. Specifically, the integration of GNMs and electrochemical biosensors has created various ingenious biosensing strategies for applications in the areas of food safety and clinical diagnosis [25].

Despite the great potential of GNMs and polymer nanocomposites, conventional nanocomposite methods including solvent processing, in situ polymerization and the allied processing encounter several issues such as the agglomeration and aggregation of graphene in the polymer matrix solution, the reduction of the electrical and mechanical properties of GNMs as a results of the insulating polymer matrix and poor dispersion of GNMs nanofillers. The aggregation of graphene is caused by its strong intermolecular $\pi-\pi$ interaction, and van der Waals forces resulting in a poor dispersion in the polymer matrix $[26,27]$. To circumvent these obstacles, electrospinning provides a facile and effective way of incorporating GNMs [28, 29] e.g. GO sheets with very high aspect ratios into the polymer solution overcome the problem of agglomeration since the polymer matrix is converted to nanosized fibers instead of continuous sheets, thus facilitating better dispersion of the exfoliated GO [30]. More importantly, properties such as porosity, elasticity, hydrophobicity, mechanical strength, percolation limit and conductivity can also be tuned by controlling the nanofiller size as well as the electrospinning parameters and solution parameters [31]. Apart from this, GNMs can be decorated on the surface of electrospun nanofibers (ESNFs) using post-processing methods enabling the possibility to fabricate multifunctional GNMs nanostructures with novel and/or improved biosensing performance. GNMs-polymer nanocomposites prepared by electrospinning possess both the advantages of polymers such as lightweight, flexibility and moldability, and special functionality of GNMs such as high strength, thermal stability and electrochemical properties [32]. Furthermore, the functionality and the dispersity of GNMs can be further improved by incorporating secondary phases such as precious metals, metal oxides, gold nanoparticles, CNTs, and hydroxyapatite either during electrospinning or in the post-processing methods, e.g. wet chemical treatment [33]. Owning to their remarkable properties, synergy effect, unique structures and the excellent electron and mass transportation, the ESNFGNMs composites are potential candidates to improve current technology and open the door to fabricate and commercialize extremely miniaturized new generation biosensors and smart wearable electronics for 
point-of-care detection in biomedicine and healthcare fields $[1,34,35]$.

Electrospinning (electrostatic spinning) involves an electrohydrodynamic process, during which a liquid droplet is electrified to generate a jet, followed by stretching and elongation to generate fibers [36]. Electrospinning setup comprises four essential components namely, a spinneret with a metallic needle (a hypodermic needle with blunt tip) and capillary tube, a syringe pump, a high-voltage-power supply, and a grounded (conductive) metal collecting screen (e.g. aluminum alloy) [37]. The procedure of electrospinning can be elucidated based on four main stages which are electrification, jet initiation and extension, bending instability and further elongation, and solidification of the jet into fibers [38]. ESNFs diameter and morphology play an essential role in constructing biosensors and are controlled by the process parameters (applied voltage, receiving distance and feed rate), solution and solvent conditions (viscosity, concentration, conductivity, surface tension, volatility) and ambient conditions (humidity, temperature, pressure) [28]. Electrospinning has been extensively reviewed with respect to its development, principle and fundamentals, and the critical parameters influencing the fiber diameter and morphology in several recent reviews such as [34, 39-45].

Due to the lack of comprehensive reviews on electrospinning design of GNMs for electrochemical biosensors, this overview aims to adequately exploit the role of electrospun GNMs nanocomposites for designing electrochemical biosensors and sensors with high sensitivity, selectivity and with low detection limits. Additionally, impregnating GNMs into ESNFs either during electrospinning process using pre-processing methods or after electrospinning as surface modification and functionalization using post-processing methods are presented. Besides, the properties of electrospun GNMs nanocomposites (electrochemical, mechanical, thermal stability and electrical conductivity) and their role in electrochemical biosensors design are critically addressed. This review covers a range of electrochemical biosensors and sensors are using electrospun GNMs nanocomposites for the detection of various analytes.

\section{Graphene-based Nanomaterials (GNMs)}

Graphene (the first ever reported 2D paper like lightweight material) is a $\mathrm{sp}^{2}$ hybridized carbon atoms that are tightly arranged into hexagonal structures to form a 2D monolayer of graphitic structure analogous to a polycyclic aromatic hydrocarbon of quasi infinite size [46]. As a basic building block of other carbon dimensionalities (allotropes), graphene can be wrapped to generate $0 \mathrm{D}$ "buckyballs" (e.g. fullerenes), rolled up to form 1D nanotubes, and stacked to produce 3D graphite [47-49]. Since its discovery in 2004 [50], graphene has been recognized as a "wonder material" mainly due to its atomic crystal multifunctionality which combines remarkable properties such as high electron mobilities in room temperature $\left(250,000 \mathrm{~cm}^{2} / \mathrm{V} \mathrm{s}\right)$ at electron densities of $2 \times 10^{11} \mathrm{~cm}^{2}[51,52]$, unparalleled thermal conductivity in the order of $5000 \mathrm{~W} / \mathrm{mK}$ [53], superlative mechanical strength (Young's modulus of $\sim 1 \mathrm{TPa}$ ) [54], large surface area $\left(2630 \mathrm{~m}^{2} / \mathrm{g}\right)$ [55], and electronic properties, making it attractive for several applications including sensors, biosensors, electronic devices, supercapacitors, spintronic, photonics, flexible and next generation electronics, biomedical applications, energy storage and solar cells [46, 56-65].

There are excellent recent reviews on the use of graphene for medicine and biology applications [66], graphene metal nanocomposites for electrochemical biosensing applications [67], graphene nanocomposites for various applications [68], graphene based biosensors for food contaminates detection [69], graphene for biosensors [70-74], electrochemical sensors [75-79] and sensors [80-82] for biomedical and other downstream applications [73, 77, 78, 83-88].

\subsection{GNMs fabrication}

GNMs include 2D, 3D graphene sheets, GO, rGO, and GQDs can be prepared following two types of fabrication methods: (i) top-down and (ii) bottom-up approaches (Fig. 1a) [89]. The former approach relies on exfoliating stacked layers of graphite by chemical, physical, and thermal treatments to form graphene and it includes micromechanical exfoliation [50], supramolecular assembly [90], conducting polymers [91] and water-soluble polymers [92]. The latter includes chemical vapor deposition (CVD) and chemical synthesis methods [93, 94]. The electrochemistry of graphene and its derivatives depends on the number of defects, functional groups, stacked layers, size of graphene sheets and dopants or impurities present [95-100]. CVD is a vacuum deposition process used to harvest graphene sheets (single or multilayer) with high quality, fine aromatic structures with limited defects, compact constitutes, high reactive surface, electrical conductivity and elasticity making it highly attractive for electrochemical sensing [101] and bioelectrodes to detect molecules and bio-organisms [58, 102-105]. Single-layer graphene (SLG) possess higher electron conductivity at room temperature $\left[250,000 \mathrm{~cm}^{2} /(\mathrm{V} \mathrm{s})\right][106]$, thus promoting its applicability for electronics and optoelectronic devices. In principle, the CVD procedure is the shortest and most useful method that allows growing graphene flakes on several substrates (transition metals) 


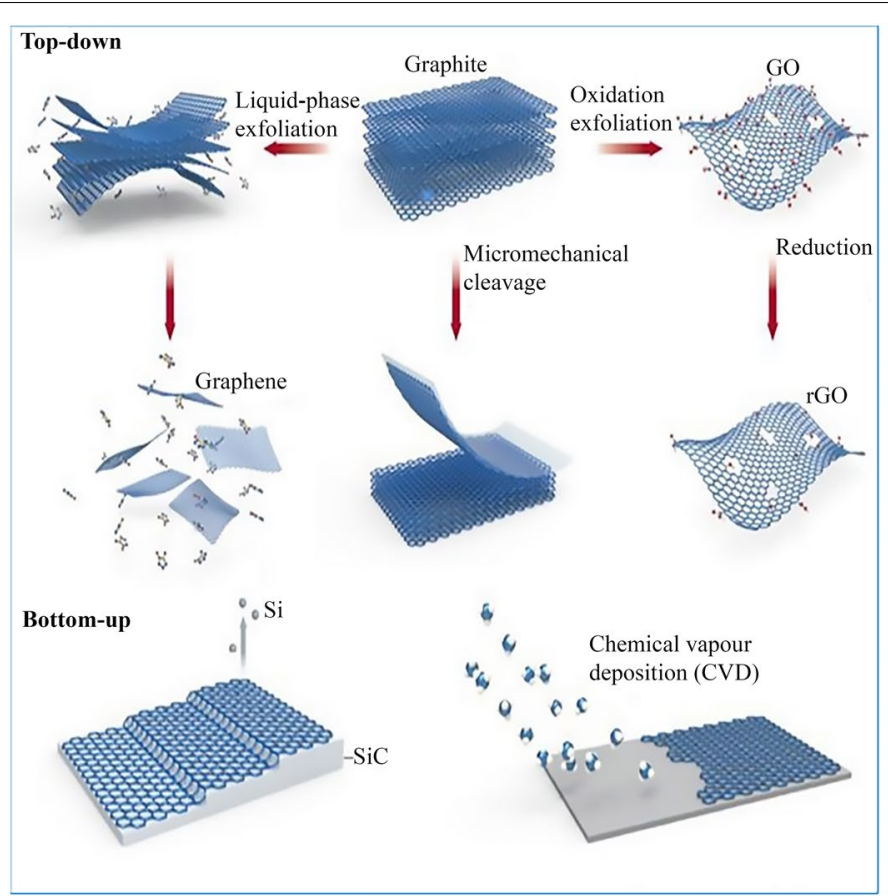

$\mathbf{a}$
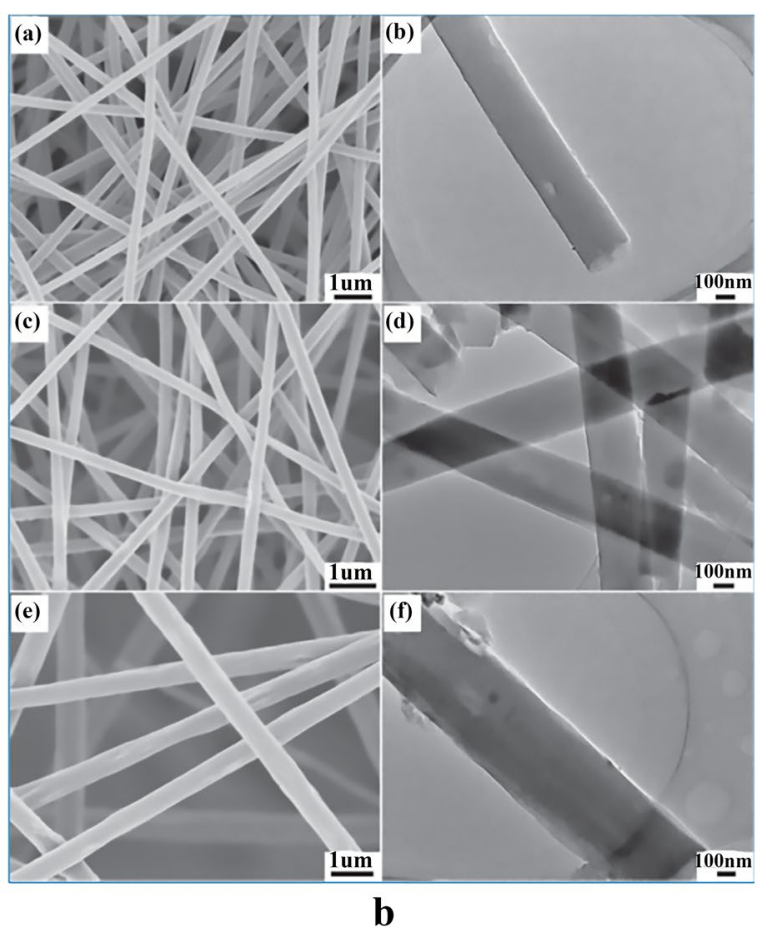

Fig. 1 a Major fabrication methods of graphene: Top-down and bottom-up fabrication methods. Principal top-down methods include liquid-phase exfoliation and micromechanical cleavage of graphite. An additional method involves the exfoliation of initially oxidized graphite, leading to GO, which is chemically and/or thermally reduced to graphene. The bottom-up fabrication of graphene is usually performed by epitaxial growth on $\mathrm{SiC}$ or chemical vapour deposition, typically on Cu using small molecules, such as methane, as precursors. Reproduced with permission from [174] Copyright 2017 Nature Publishing Group. b SEM (a, c, e) images and TEM images (b, d, f) of nanofibers (a, b), nanofibers-rGO-5 (c, d), and nanofibers-rGO-10 (e, f) with different magnifications Reproduced with permission from [173] Copyright 2019 Wiley

such as $\mathrm{Ge}[107,108], \mathrm{Ni}[109,110], \mathrm{Cu}[111,112], \mathrm{Rh}$ $[113,114]$, and etc.

Hummer's method is a top-down approach to fabricate high-quality and scalable oxidized graphene sheets with different nanosized, good solution process-ability, oxygen content, and sheet layers [115]. GO is an excellent form of graphene [116] having a simultaneous hydrophobic $\mathrm{sp}^{2-}$ and $\mathrm{sp}^{3-}$ bonded carbon and abundant carboxylic acid groups, epoxide and hydrophilic hydroxyl, especially on the edge and defects of the nanosheet, hence forming a sheet-like amphiphilic colloid [117]. GO, due to its abundant residual $\mathrm{sp}^{2-}$ and hydrophilic groups can form stable suspension in aqueous and several polar solvents and form $\pi-\pi$ interactions with aromatic molecules [118]. Furthermore, the polar chemical groups, carboxyl acid, epoxide, and hydroxyl on the basal plane allow GO to undergo weak interactions for example strong electrostatic interactions or hydrogen bonding and metal ion complexes which also provide abundant chemically reactive groups for surface grafting/anchoring of polymers and or nanoparticles [2]. The oxidized functional groups of GO improve its dispersion in polymer matrices and minimize the aggregation and phase separation. GO, due to its amphiphilic sheet-like characteristics acts as a surfactant reagent to react with other nanomaterials [117]. RGO, can be obtained by chemical or physical reduction of $\mathrm{GO}$ by thermal, chemical, and irradiation methods which are cost-effective approaches to fabricate graphene sheets with a good electrical conductivity. Compared to graphene and GO, rGO has more balanced physical and chemical properties regarding surface chemical groups, electrical, mechanical, solvent dispersibility, optical, and thermal performances [118]. Due to these properties, rGO nanosheets are potential candidates for the next-generation electronics, sensors and transistors. GQDs are nanometer-sized single layer-fragments (their sizes are less than $20 \mathrm{~nm}$ in diameter) of graphene and GO, which are typically synthesized via a top-down approach through "cutting" of graphene or GO nanosheets [119]. GQDs exhibit several remarkable physical properties such as the edge defects induced luminescence and the quantum confinement, making GQDs suitable for interesting 
applications including cell imaging, bioelectrodes and molecular recognition [120-122].

\section{Electrospun nanofibers containing GNMs}

Research pertaining to electrospinning has gained significant traction in recent years, as it provides a versatile and viable tools for generating various matrices in a continuous process and with uniform pore sizes, where the fiber diameters are adjusted from nanometers to sub-microns $[40,123,124]$. ESNFs with diameters lower than $1 \mathrm{~nm}$ (subnanometers) have also been recently reported [125, 126]. Although, there are several analogous nanofiber production methods such as nanolithography, selfassembly, melt fibrillation, drawing and template synthesis, electrospinning combines simplicity, low cost and versatility with superior capabilities to manufacture high quality nanofibers with diverse and controlled morphologies and complex nanofibrous assemblies [127-129]. Electrospinning has been successfully applied to produce nanofibers from a wide range of materials, including organic and inorganic polymers, ceramics, metals, graphene, carbon nanotubes, small molecules, and their combinations as well as bacteria, viruses, biomolecules $[40,130,131]$. The incorporation of GNMs into ESNFs enables significant enhancement towards biosensing capability either by improving the response characteristic of the transducer or acting as the immobilisation matrix for a bioreceptor [132]. GNMs can be incorporated into the ESNFs using two main strategies: (i) pre-processing methods (direct blending and in situ synthesis) and (ii) post-processing methods (e.g. physical dip-coating, ultrasonication, plasma treatment, wet chemical method and radiation treatment $[68,133]$.

\subsection{Electrospinning design of GNMs NF composites using pre-processing methods}

Introducing GNMs into the polymer solution matrices for electrospinning is a simple and effective method to fabricate electrospun composites for various advanced applications such as sensing and biosensing [28]. In principle, the pre-processing methods consider the size distribution and interface interactions during the encapsulation of GNMs within the polymer nanofibers. In this case, the GNMs should be more stable to ensure the long-term storage stability and excellent reusability of the GNMs ESNFs composite biosensors. In GNMs ESNFs prepared by the pre-processing methods for electrochemical biosensing applications, the GNMs act as the electron transfer platform while the polymers act as a selective adsorptive for bio-tests thus both GNMs and polymers work as a device for electrochemical biosensor electrode. GNMs ESNFs act as a bridge between the test biomolecules and the signal transduction system and thus plays a critical role in both sensor and conductor parts of electrochemical biosensors. High dispersion and even distribution of GNMs within the polymer matrices enable the fabrication of nanofiber composites with highly functional nanofiber composites, novel hierarchical architectures, high specific surface area and tuned porosity, excellent chemical, thermal, electrical and electrochemical properties offering unparalleled performance for point-of-care detection and lab-on-chip devices [132]. There are two effective strategies to ensure uniform distribution of GNMs into polymer nanofibers; the direct blending or mixing of GNMs with polymer matrix before electrospinning and in situ synthesis during electrospinning.

\subsubsection{Direct blending of GNMs in polymer nanofibers}

Blending of GNMs into polymer matrix solution is the basic and straightforward way to fabricate GNMs NFs composites. In this strategy, the direct doping of GNMs into polymer matrix may decrease the surface energy of GNMs which in turn tends to cause local cross-linking between GNMs and polymers. In the case of electrochemical biosensors, the even distribution and dispersion of GNMs within the polymer solution matrices is an essential attribute for improving the linear detection range, sensitivity and limit of detection. Therefore, other ways to improve the dispersity and homogeneity of GNMs within the polymer solution matrices should be investigated.

\subsubsection{Dispersing GNMs using external forces}

One of the main challenges in fabricating nanofibers GNMs is the fact that they have high specific surface area and free energy and tend to agglomerate and/or aggregate which compromise their final performances for biosensor applications [20]. The agglomeration of GNMs may be ascribed to their short-range interactions with the polymeric molecules and the overlapping of interfacial layers of neighbouring graphene nanofillers or polymers. Therefore, if GNMs are not well dispersed and distributed into the polymer matrices at a nanoscale level, the weak molecular interactions take place and the inhomogeneous dispersion may complicate the electrospinnability of solutions, thus reducing the graphene loading capacity and influencing the overall material properties. To overcome these issues, treating the solution with an external force to aid dispersity of GNMs such as manifold repetition of blending and violent stirring, ultrasonic dispersion methods (ultrasonication bath and ultrasonication probe) or by modifying the surface of graphene materials with active surface agents (adding additive to promote the dispersity of GNMs). Adding 
additives allows mitigating the huge gap in surface energy between the GNMs and the polymer matrices to obtain a better solvability and suitable nano-scaled distribution thus improving their spinnability. Several spacers have been introduced into GNMs to improve the dispersity and to enhance the specific surface area to provide extra adsorption sites for bio and sensing molecules such as metals and metal oxide nanoparticles [134, 135], organic moieties [136, 137], and polymers [134, 135]. Functionalization of graphene using chemical, electrochemical and sonochemical methods improved its dispersion within polymer matrices, for example functionalized graphene such as GO enhances its dispersion in various polymer matrices due to the interfacial interactions between the functionalized graphene and the polymer $[138,139]$. Several studies have used external forces and/or adding additives to improve the dispersity and distribution of GNMs in polymer matrix as reported in Table 1.

\subsubsection{In-situ synthesis of GNMs in polymer nanofibers}

Similar to blending, the in situ synthesis is an effective strategy to disperse GNMs into the polymer solution to form GNMs NF composites using several methods such as hydrothermal reaction, sol-gel synthesis, oxidation-reduction reaction and hydrolysis. In this strategy, GNMs dispersity in the polymer matrix can be assisted using reactions triggered by light, heat, electrochemistry and reactive additives to uniformly distribute GNMs ions inside the polymer matrix with controlled sizes and uniformity while avoiding the agglomeration of GNMs. Sahatiya and Badhulika [168] reported a facile one step method for in situ synthesis and alignment of a single graphene-doped zinc oxide electrospun nanofiber composite. They optimized the calcination temperature and the time-dependent electrospinning to fabricate aligned graphene- $\mathrm{ZnO}$ composite nanofibers across the gold electrode. The reported method is a cost-effective to detect UV and it can be extended to a variety of sensing applications. He et al. [169] reported in situ synthesis, carbonization and electrospinning to fabricate porous graphene-doped copper indium disulfide/carbon (p-GN@CuInS ${ }_{2} / \mathrm{C}$ ) composite nanofibers in which graphene nanosheets anchored with $\mathrm{CuInS}_{2}$ nanocrystals of $7-12 \mathrm{~nm}$ in diameter were overlapped and embedded in a carbon matrix, aligning along the fiber axial direction. The resultant graphene nanofiber composite exhibited smaller charge-transfer resistance, larger surface area, and excellent electrocatalytic activity than $\mathrm{CuInS}_{2} / \mathrm{C}$ and $\mathrm{p}-\mathrm{CuInS}{ }_{2} / \mathrm{C}$ samples.

\subsubsection{Dispersion of GNMs using electrospinning}

Electrospinning applies electrostatic stretching forces to overcome any entanglement and agglomeration of GNMs by increasing their interface contact with the polymer matrix thereby making possible chemical bonds between them. It also provides shear stress transfer mechanics from the polymer matrices to the nanometric of GNMs thus improving the dispersion of GNMs and prevents their aggregation. Additionally, during the electrospinning, the high elongation of the polymer jet improves the orientation and alignment of GNMs along the fiber axis and embeds them in the fiber core thereby achieving highly distributed GNMs-ESNF composites. The content of GNMs influences their dispersion and induces the changes to the solution rheological and physical properties such as electrical conductivity and viscosity and the diameter of the nanofibers. For instance, the increase of GNMs content induces a higher viscosity which in turn results in forming thicker fibers. Meanwhile, the electrical conductivity will rise with the increase of the GNMs content which favours the stretching of thinner fibers [170]. Due to these opposite behaviors, some studies have shown variable fiber diameters as the loading of the nanomaterial is increased [170, 171]. Recently, [172] reported a dual method comprising of electrospinning and electrospraying to overcome the difficulty of blending and dispersing polyacrylonitrile (PAN) and GO in the same solvent. Shan et al. [173] reported the fabrication of a free-standing nitrogen-doped reduced graphene oxide nanofibers using electrospinning technique. The developed nanofibers showed high electronic conductivity and thus has the potential to be used for chemical sensing, separation and drug delivery. Figure 1b) depicts the scanning electron microscope (SEM) results for the developed PAN-GO ESNF mats.

\subsection{Electrospinning design of GNMs NF composites using post-processing methods}

Although direct blending of GNMs is the simplest and most effective method, one of the critical limitations of blending GNMs into the polymer solution is that asprepared nanofiber composites may show relatively low-conductivity because the conductivity of GNMs could be warped within the insulating polymers. Alternative approach is to impregnate GNMs onto the surface of ESNFs after electrospinning process using the surface modification methods (post-processing methods). This approach aims at avoiding the problems associated with pre-mixing GNMs into the polymer matrix (e.g. agglomeration and low conductivity) and providing a robust strategy to improve the physiochemical and biological properties of ESNFs. In principle, post-processing methods impregnate or coat GNMs on the surface of the desired ESNFs using chemical or physical strategies to alter the surface of the nanofibers by giving them new features (e.g. surface activation, enhancing surface 
Table 1 Summary of recent significant works on electrospinning design of GNMs with polymer matrices using preprocessing methods

\begin{tabular}{|c|c|c|c|c|c|c|}
\hline GNMs & Polymer & Solvent & Additives & $\begin{array}{l}\text { Dispersion method/ } \\
\text { external force }\end{array}$ & $\begin{array}{l}\text { ES parameters: } \\
\text { (distance; voltage; } \\
\text { federate) }\end{array}$ & Refs. \\
\hline GO & PVDF & $\begin{array}{l}\text { DMF: acetone } \\
4: 1 \mathrm{wt} / \mathrm{wt} \%\end{array}$ & - & $\begin{array}{l}\text { Hydrophobic modi- } \\
\text { fication of GO with } \\
\text { subsequent sonica- } \\
\text { tion and stirring }\end{array}$ & $\begin{array}{l}(27.7 \mathrm{~cm} ; 24.1 \mathrm{kV} ; \\
\quad 1.23 \mathrm{~mL} / \mathrm{h})\end{array}$ & [140] \\
\hline rGO & PANCMA & DMF & $\mathrm{TiO}_{2}$ & $\begin{array}{l}\text { Ultrasonication and } \\
\text { microwave heating }\end{array}$ & $\begin{array}{c}(30 \mathrm{~cm} ; 14 \mathrm{kV} \\
0.02 \mathrm{~mL} / \mathrm{h})\end{array}$ & [141] \\
\hline GO & $\begin{array}{l}\text { Poly (lactic acid) (PLA)/ } \\
\text { poly(butylene car- } \\
\text { bonate) }\end{array}$ & DMF solvent & PBC & Stirring & $18 \mathrm{kV}$ & [142] \\
\hline GO & $\mathrm{PCL}$ & DMF: DCM 1:1 & - & Stirring & $14 \mathrm{~cm} ; 18 \mathrm{kV} ; 10 \mathrm{~mL} / \mathrm{h}$ & [143] \\
\hline rGO & $\begin{array}{l}\text { poly (ester amide) } \\
\text { (PEA) }\end{array}$ & & & Ultrasonication bath & $\begin{array}{l}(12 \mathrm{~cm} ; 20 \mathrm{kV} ; \\
0.1 \mathrm{~mL} / \mathrm{h})\end{array}$ & [144] \\
\hline GR & PLA & $\begin{array}{l}\text { DCM:TFA } \\
2: 1 \mathrm{v} / \mathrm{V}\end{array}$ & - & Ultrasonication & $\begin{array}{l}(15 \mathrm{~cm} ; 10-20 \mathrm{kV}, \\
2 \mathrm{~mL} / \mathrm{h})\end{array}$ & [33] \\
\hline GR & PU & $\begin{array}{l}\text { THF: DMAC } \\
3: 2 \mathrm{w} / \mathrm{v}\end{array}$ & - & Ultrasonication & $(10 \mathrm{~cm} ; 15 \mathrm{kV} ; 1 \mathrm{~mL} / \mathrm{h})$ & [145] \\
\hline GO & PAN & DMF & - & $\begin{array}{l}\text { Probe and bath soni- } \\
\text { cation and stirring }\end{array}$ & $\begin{array}{l}(15 \mathrm{~cm} ; 18 \mathrm{kV} \\
0.2 \mathrm{~mL} / \mathrm{h})\end{array}$ & [146] \\
\hline Gr & 66nylon & $\begin{array}{l}\text { TFA: acetone } \\
1: 1 \mathrm{v} / \mathrm{V}\end{array}$ & - & $\begin{array}{l}\text { Bath and tip sonica- } \\
\text { tion }\end{array}$ & $\begin{array}{l}(15-20 \mathrm{~cm} ; 15-20 \mathrm{kV} ; \\
0.17 \text { to } 0.5 \mathrm{~mL} / \mathrm{h})\end{array}$ & [147] \\
\hline $\mathrm{Gr}$ & Polycaprolactone & DMF & - & Stirring & $\begin{array}{l}(10 \mathrm{~cm} ; 10-14 \mathrm{kV} ; \\
0.4-0.5 \mathrm{~mL} / \mathrm{h})\end{array}$ & [148] \\
\hline GO & PLGA & $\begin{array}{l}\text { 1,1,1,3,3,3-Hexafluor- } \\
\text { oisopropanol (HFIP) }\end{array}$ & - & Stirring & $\begin{array}{l}(10 \mathrm{~cm} ; 40 \mathrm{kV} ; \\
0.07-0.1 \mathrm{~mL} / \mathrm{min})\end{array}$ & [149] \\
\hline GO/MWCNT & PEO & DMF & & $\begin{array}{l}\text { Sonication and vigor- } \\
\text { ous stirring }\end{array}$ & $\begin{array}{l}(15 \mathrm{~cm} ; 18.4 \mathrm{kV} \\
0.5 \mathrm{~mL} / \mathrm{h})\end{array}$ & [150] \\
\hline GR & Polyamide 66 & Formic acid & - & Stirring & $\begin{array}{l}(15 \mathrm{~cm} ; \\
\quad 20 \mathrm{kV} ; 0.25 \mathrm{~mL} / \mathrm{h})\end{array}$ & [151] \\
\hline GO & PVDF & DMF & - & Sonication and stirring & $(15 \mathrm{~cm} ; 18 \mathrm{kV} ; 1 \mathrm{~mL} / \mathrm{h})$ & [152] \\
\hline GO-ZnO & $\begin{array}{l}\text { Gum arabic (GA) and } \\
\text { PVA }\end{array}$ & & - & Stirring and heating & (130 mm; 0-50 kV) & [130] \\
\hline GO & Polyurethane (PU) & DMF & $\mathrm{Ag}$ & Stirring and heating & $(18 \mathrm{~cm} ; 18 \mathrm{kV} ; 1 \mathrm{~mL} / \mathrm{h})$ & [153] \\
\hline $\mathrm{GO}$ & $\begin{array}{l}\text { poly(Acrylonitrile-co- } \\
\text { maleic acid }\end{array}$ & DMF & - & $\begin{array}{l}\text { Microwave heating } \\
\text { and ultrasonication }\end{array}$ & $(12 ; 25 \mathrm{kV} ; 0.03 \mathrm{~mL} / \mathrm{h})$ & [154] \\
\hline Graphene Nano sheets & $\begin{array}{l}\text { poly (Trimethylene } \\
\text { terephthalate) }\end{array}$ & TFA & - & Stirring & $(14 \mathrm{~cm} ;$ & [155] \\
\hline GO & CA & $\begin{array}{l}\text { DMF: acetone } \\
\text { 2:3 wt/wt } \%\end{array}$ & - & $\begin{array}{l}\text { Sonication and heat- } \\
\text { ing and stirring }\end{array}$ & $\begin{array}{c}(15 \mathrm{~cm} ; 27 \mathrm{kV} ; \\
0.13 \mathrm{~mL} / \mathrm{h})\end{array}$ & [156] \\
\hline GO & PLA & DMF & - & Stirring & $(6 \mathrm{~cm} ; 20 \mathrm{kV} ; 1 \mathrm{~mL} / \mathrm{h})$ & [157] \\
\hline rGO & Polystyrene (PS) & (DMF:THF) 1:1 & - & Magnetic stirrer & $22 \mathrm{kV}$ & [158] \\
\hline GQD & PAN & DMF & - & DMF Magnetic stirring & $\begin{array}{c}240 \mathrm{~cm} ; 15 \mathrm{kV} ; \\
0.63 \mathrm{~mL} / \mathrm{h}\end{array}$ & [159] \\
\hline GO & CA & $\begin{array}{l}\text { Acetone/DMAc (w/w } \\
\text { 2:1) }\end{array}$ & - & Stirring & $\begin{array}{l}(8-10 \mathrm{~cm} ; 20-25 \mathrm{kV} ; \\
\quad 1.5 \mathrm{~mL} / \mathrm{h})\end{array}$ & [160] \\
\hline $\begin{array}{l}\text { Fluorine-doped GO, } \\
\text { GO, and GOCOOH }\end{array}$ & PVDF & $\begin{array}{l}\text { DMAC: acetone ( } / \mathrm{V} \\
\text { 4:6) }\end{array}$ & $\begin{array}{l}1 \mathrm{~g} \text { of selectfluor } \\
\text { and } 0.1 \mathrm{~g} \text { silver } \\
\text { nitrate }\end{array}$ & Stirring & $\begin{array}{l}(12 \mathrm{~cm} ; 25 \mathrm{kV} \\
0.5 \mathrm{~mL} / \mathrm{h})\end{array}$ & [161] \\
\hline rGO & PVP/Chitosan & $\begin{array}{l}\text { Acetic acid: water } \\
\text { 9:1 (w/v) }\end{array}$ & - & Stirring & $(6 \mathrm{~cm} ; 22 \mathrm{kV} ; 0.5 \mathrm{~mL} / \mathrm{h})$ & [162] \\
\hline rGO & PMMA/PANI & DMF & & Stirring and sonication & $\begin{array}{l}(15 \mathrm{~cm} ; 18-20 \mathrm{kV} ; \\
0.3 \mathrm{~mL} / \mathrm{h})\end{array}$ & [163] \\
\hline GO & PLA/PCL & $C F: D M F(v / v=4 / 1)$ & - & $\begin{array}{l}\text { Magnetic stirring and } \\
\text { sonication }\end{array}$ & $(20 \mathrm{~cm} ; 20 \mathrm{kV})$ & [164] \\
\hline GR & PVDF & & & Sonication and stirring & $(17 \mathrm{~cm} ; 20 \mathrm{kV} ; 1 \mathrm{~mL} / \mathrm{h})$ & [165] \\
\hline
\end{tabular}


Table 1 (continued)

\begin{tabular}{|c|c|c|c|c|c|c|}
\hline GNMs & Polymer & Solvent & Additives & $\begin{array}{l}\text { Dispersion method/ } \\
\text { external force }\end{array}$ & $\begin{array}{l}\text { ES parameters: } \\
\text { (distance; voltage; } \\
\text { federate) }\end{array}$ & Refs. \\
\hline GR & $\mathrm{PCL}$ & Acetic acid & Gelatin & Sonication and stirring & $\begin{array}{l}(15 \mathrm{~cm}, 10-20 \mathrm{kV} \\
0.2-1.8 \mathrm{~mL} / \mathrm{h})\end{array}$ & {$[166]$} \\
\hline Gr and GO & PVDF & & & $\begin{array}{l}\text { Ultrasonication probe } \\
\text { (100 W, } 40 \mathrm{kHz}, 15 \\
\text { mints) }\end{array}$ & $\begin{array}{l}(100 \mathrm{~mm} ; 16 \mathrm{kV} ; \\
2 \mathrm{~mL} / \mathrm{h})\end{array}$ & {$[167]$} \\
\hline
\end{tabular}

conductivity) [175]. This induce large number of active sites for further biomolecular immobilization while considering the surface properties of the nanofibers which mainly depends on the chemical composition of the spinning solution and the surface structure of the fibers [176]. This approach is essentially simple and easy to implement and is economically more feasible at an industrial scale than direct mixing of polymers with GNMs. It is worth noting that the arrangement of GNMs should be made to transfer more GNMs to the electrospun polymer nanofiber surface to increase the chance of the interaction between GNMs and bio-analyses which is of great benefit for biosensors [177]. The methods for incorporating electrospun nanofibers with GNMs for sensing applications include physical adsorption and coating, surface graft polymerization, layer-by-layer, plasma modification, chemical doping, heteroatoms doping, wet chemical methods etc. Table 2 summarizes the recent post processing methods used to impregnate ESNFs with GNMs.

Among the simplest, fastest and easiest methods to endow electrospun nanofibers with GNMs active sites for target interactions is through the physical dip-coating. This method relies on the interaction between the sensitive probe molecules and the nanofibers which often

Table 2 Summary of recent significant works on electrospinning design of GNMs with polymer matrices using postprocessing methods

\begin{tabular}{|c|c|c|c|c|c|}
\hline GNMs & ES NFs & Postprocessing method & Mechanism & Potential applications & Refs. \\
\hline Ag-AQGO & PEO/PVA & Wet chemical route method & $\begin{array}{l}\text { The ESNFs were immersed into the as- } \\
\text { prepared Ag-AQRGO solution to self- } \\
\text { assemble the negatively Ag-AQRGO } \\
\text { onto the positively charged NFs in an } \\
\text { aqueous solution. The Ag-AQRGO was } \\
\text { further washed away with deionized } \\
\text { water. After drying in air, the AgNP- } \\
\text { 3D-AQRGO sensor was obtained }\end{array}$ & Gas sensors & {$[32]$} \\
\hline PEDOT-CNT/rGO & PVDF-TrFE & Spray coating & $\begin{array}{l}\text { PEDOT-CNT/rGO is decorated on ES } \\
\text { PVDF-TrFE NFs following these steps: } \\
\text { 1. Functionalization of PVDF-TrFE ES } \\
\text { NF: using dip coating of ethanol, } \\
\text { potassium hydroxide and potassium } \\
\text { permanganate and finally hydrogen } \\
\text { peroxide. } \\
\text { 2. Spraying of the positively charged } \\
\text { MCNTs suspension and negatively } \\
\text { biased rGO solution on the functional- } \\
\text { ized PVDF-TrFE ESNF } \\
\text { 3. Coating of PEDOT on the substrate } \\
\text { to further enhance the electrical } \\
\text { conductivity and sensitivity. }\end{array}$ & $\begin{array}{l}\text { Piezo-electric pressure sensor and wear- } \\
\text { able smart textiles }\end{array}$ & {$[33]$} \\
\hline rGO & $\mathrm{PVP} / \mathrm{InCl}_{3}$ & Ultrasonic dispersion & $\begin{array}{l}\text { The hybrid nanofibers (NFI-rGO) were } \\
\text { obtained via ultrasonic dispersion of } \\
2 \mathrm{mg} \mathrm{NFI} \mathrm{in} \mathrm{a} \mathrm{rGO} \mathrm{aqueous} \mathrm{suspen-} \\
\text { sion }\left(0.1 \mathrm{mg} \mathrm{mL}^{-1}\right) \text { for } 5 \text { min }\end{array}$ & $\begin{array}{l}\text { Gass sensing in different environments. } \\
\text { with } 44 \text { ppb detection limit and a } \\
\text { response time of } 17 \mathrm{~s}\end{array}$ & {$[34]$} \\
\hline rGO & PVA & $\begin{array}{l}\text { Cross linking and chemical } \\
\text { radiation modification } \\
\text { method }\end{array}$ & $\begin{array}{l}\text { The PVA nanofibers were crosslinked (to } \\
\text { make them stable and water resistant) } \\
\text { with UV-light of } 253.7 \mathrm{~nm} \text { (UV-340 } \\
\text { lamp) at } 30 \text { W with different duration } \\
(15,30,45 \text { and } 75 \text { min) and then they } \\
\text { were kept in both water and PBS solu- } \\
\text { tions to optimize crosslinking duration }\end{array}$ & $\begin{array}{l}\text { Filtration, sensors/biosensors, thin films } \\
\text { and packaging }\end{array}$ & {$[35]$} \\
\hline
\end{tabular}


involves van der Waals forces, hydrophobic forces, electrostatic forces, and hydrogen bonding [178]. However, the efficiency and strength of biomolecular immobilization in this case is relatively weaker [179]. To overcome this limitation, plasma treatment method enables increasing the efficiency of physical absorption onto the hydrophobic nanofibers by creating a more hydrophilic surface thus enhancing biomolecules attachment because of the large availability of carboxyl and hydrophilic surface groups. Layer-by-layer method offer a versatile method to modify the surface of ESNFs by utilizing electrostatic attraction to manipulate the physiochemical, mechanical and biological properties assemble polyelectrolyte multilayers allowing nanoscale control over composition and structure. Chemical doping with atoms is an effective strategy to obtain intrinsic modification of carbon nanomaterials to improve their electrochemical properties [180].

Recently, [181] prepared pristine $\mathrm{SnO}_{2}$ nanotubes (NTs) by one-step electrospinning and GO was doped into the as-prepared $\mathrm{SnO}_{2}$ NTs nanofibers by calcination treatment as shown in Fig. 2(1). First the prepared electrospun $\mathrm{SnO}_{2}$ nanotube fibers were annealed at $600{ }^{\circ} \mathrm{C}$ for $2 \mathrm{~h}$ to remove polymers and the organic residuals and to oxide the inorganic precursors into $\mathrm{SnO}_{2}$ nanostructures. Next, $0.03 \mathrm{~g}$ of pristine $\mathrm{SnO}_{2}$ NTs bundles were dipped into $1 \mathrm{ml}$ of GO (mixed in DI water) solution and dried in the air for several hours. Finally, GO-loaded
$\mathrm{SnO}_{2}$ were obtained after thermal annealing at $200{ }^{\circ} \mathrm{C}$. SEM images are presented in Fig. 2(2) and the obtained results revealed that the modification of $\mathrm{SnO}_{2}$ nanotubes by $\mathrm{GO}$ shows the improved sensing properties (e.g. faster response) attributed to the large interfacial interaction between the $\mathrm{GO}$ and the $\mathrm{SnO}_{2}$ NTs.

Tambakoozadeh et al. [182] utilized in situ polymerization to prepare polyaniline (PANI)/graphene-coated polyamide nanofiber composite for the electrochemical applications. The composite of PANI/GO nanofibers were treated with monohydrate to reduce GO to graphene, and this was followed by the re-oxidation of PANI. The electrical conductivity of the composite PANI/graphene-coated nanofiber was enhanced mainly due to the presence of graphene as well as the increase of aniline concentration in the polymerization process. In terms of the mechanical properties, the presence of GO enhanced the tenacity of the coated nanofibers which is ascribed to the homogenous dispersion of graphene nanosheets and thus the effective load transfer from the matrix to graphene because of their strong interfacial adhension. As for the electrochemical properties, the cyclic voltammetry $(\mathrm{CV})$ curves of the coated nanofibers at a scan of $10 \mathrm{~V} / \mathrm{s}$ and with a potential window from 0 to $0.9 \mathrm{~V}$ (Additional file 1: Figure S1).

Zheng et al. [183] assembled RGO onto the polyurethane (PU) electrospun nanofiber composite assisted by ultrasonication to obtain a polymer core-RGO shell

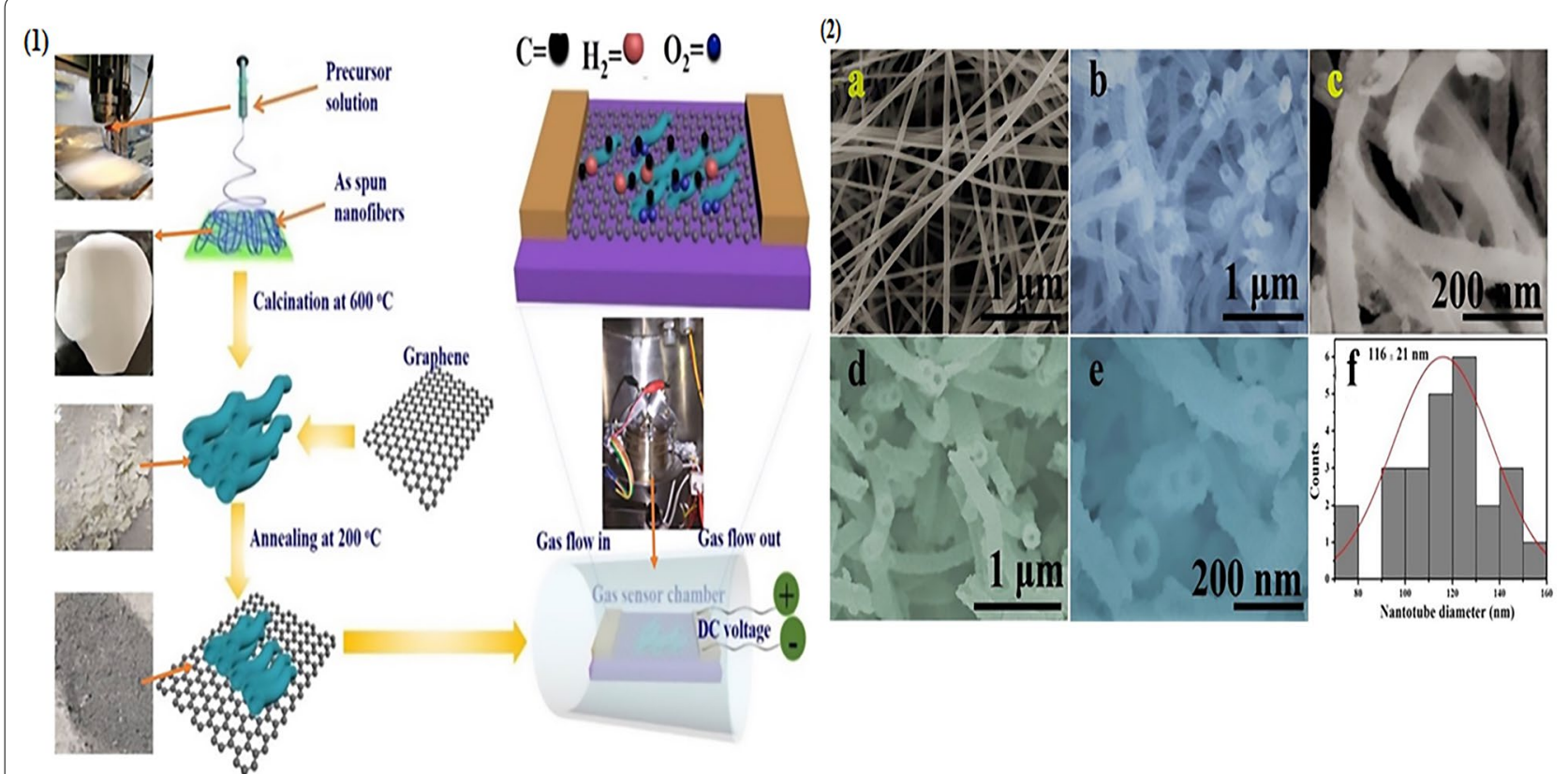

Fig. 2 (1): Pristine and GO-SnO $\mathrm{NTS}_{2}$ preparation and gas sensor mechanism and (2) SEM images of (a) as-prepared Sn+ poly (vinyl pyrrolidone) (PVP) nanofibers (b, c) pristine $\mathrm{SnO}_{2}$, and (d, e) GO incorporate $\mathrm{SnO}_{2} \mathrm{NTs}$, (f) Histogram of GO-SnO${ }_{2} \mathrm{NT}$ diameters Reproduced with permission from [181] Copyright 2019 Elsevier 
structure. First PU was dissolved in dimethylformamide (DMF) solvent and stirred for $12 \mathrm{~h}$ at $60{ }^{\circ} \mathrm{C}$ to produce a homogenous solution. The solution was then placed in a syringe and the electrospinning was processed at a flow rate of $1 \mathrm{ml} / \mathrm{h}$, a voltage of $15 \mathrm{kV}$ and the receiving distance was $15 \mathrm{~cm}$. RGO solution was prepared by dispersing RGO in ethanol, water or acetone solvents and ultrasonicated for $0.5 \mathrm{~h}$. The resultant ES PU nanofibers were dipped in the dispersed RGO solution under ultrasonication for different duration from $10 \mathrm{~s}$ to 20 min during which RGO nanosheets were gradually assembled on the nanofiber surface to form the core-shell structure. Finally, the RGO decorated composite mat was obtained after washing with ethanol and drying at $60^{\circ} \mathrm{C}$ for $12 \mathrm{~h}$. Samani et al. [148] observed an increase in the conductivity and mechanical properties when adding graphene in the polymer matrix for electrospinning. Gozutok et al. [184] dispersed rGO in the poly (vinyl alcohol) (PVA) solutions without using any co-solvent and then electrospinning was used to fabricate nanofiber mats. By adding $\mathrm{rGO}$, the properties of the PVA/rGO NF composite such as the porosity, inter fiber, pore size, and average fiber diameter were relatively improved. It was also observed that, the increase in rGO content improved the mechanical properties, thermal stability and electrical conductivity while the crystal structure of PVA did not change.

\section{Properties of electrospun GNMs nanocomposites}

ESNFs differentiate themselves by their remarkable functional features such as an extremely high surface-areato volume ratio, ultra-fine diameter, high aspect ratio of length to diameter and molecular orientation along fiber axis, a complex and large porous structure with excellent pore-interconnectivity and tunability, a great mechanical performance, diverse fibrous morphologies, physio-chemical and electrical properties and adjustable structure and diameter [31, 43]. Due to their specialized features, ultrathin diameters and controlled porosity, electrospun nanofiber have demonstrated high potential for a wide spectrum of applications that includes enhancing the performance of analytical devices, biomedical applications, sensor and biosensor technologies [40].

Impregnating GNMs into ESNFs either during the electrospinning through pre-processing or after electrospinning using post-processing methods impart the nanofibers with remarkable properties and morphological structures, useful for electrochemical sensing and biosensing. In terms of electrochemical properties, the 3D interconnected hierarchical structures of GNMs enable facilitating the diffusion of different types of biomolecules as well as maintain their biocatalytic bioactivity functions thereby improving the sensitive and functionality of biosensors. Owning to their intrinsically high strength derived from the very strong carbon bonds as well as their interactions with the polymer solution matrix and their degree of dispersion, the addition of GNMs can overwhelmingly improve the tensile strength and Young's modulus of the ESNFs. GNMs are remarkable additives to improve the mechanical and electrical properties of electrospun nanofibers [185]. Dispersion GNMs into polymer matrices have been reported to improve the electrical, mechanical, thermal properties and other properties of polyslfones [186, 187], polyimide [188, 189], polycarbonates [190, 191], polyamides [192, 193], polyethylene terephthalate $[192,193]$ and polybutylene terephthalate [194, 195]. Gorji et al. [196] reported that the incorporation of GO into electrospun of PU and $\mathrm{pH}$ - sensitive dyes contributed to a faster response (7 s) and improved the sensor's sensitivity to detect $\mathrm{pH}$ in chemical vapor solution. Table 3 summarizes the recent studies on impregnating GNMs into ESNFs and the subsequent improved properties. Choi et al. [153] reported a stretchable and transparent nanofiber-networked electrode (STNNE) based on intrinsically stretchable electrospun nanofibers of polyurethane (PU)/reduced graphene oxide (rGO)/silver nanoparticles (AgNPs) (Fig. 3). It was found that, the highly dispersed AgNPs into the PU/rGo nanofibers improved the electrical conductivity, mechanical stretchability. Furthermore, the presence of rGO and the formation of fused intersections between the nanofibers which occurred during the electrospinning process have concert improvements on the electrical stability of the fabricated STNNE. The fabricated STNNE was successfully demonstrated as a stretchable capacitive touch sensor on an elastomeric substrate.

Ruan et al. [158] reported an increase in the thermal conductivity of polystyrene (PS) as a result of the co-electrospinning of PS with thermally reduced graphene oxide (TRG). More specifically, the addition of $15 \mathrm{wt} \%$ TRG could increase the thermally conductive coefficient $(\lambda)$ value of pure PS from 0.226 to $0.689 \mathrm{~W} / \mathrm{mK}$, glass transition coefficient (a) value from 0.2157 to $0.6545 \mathrm{~mm}^{2} / \mathrm{s}$, glass transition temperature $\left(\mathrm{T}_{\mathrm{g}}\right)$ value from 90.3 to $95.0^{\circ} \mathrm{C}$ and heat-resistance index $\left(\mathrm{T}_{\mathrm{HRI}}\right)$ value from 184.2 to $194.3^{\circ} \mathrm{C}$. Gozutok et al. [184] observed that, adding rGO to PVA improved the thermal stability as shown in Fig. 4c. Abdali and Ajji [163] reported that, the thermal stability of PANI improved in the presence of graphene as shown in Fig. 4d, e.

Gebrekrstos et al. [161] reported that the addition of fluoro-doped graphene derivatives (GO, GOF and $\mathrm{GOOCH}$ ) during electrospinning of polyvinylidene fluoride (PVDF) offered remarkable properties including enhanced electroactive $\beta$ phase, high energy density and improved piezoelectric coefficient. This drastic enhancement can be ascribed to the increase in the amount of $\beta$ 


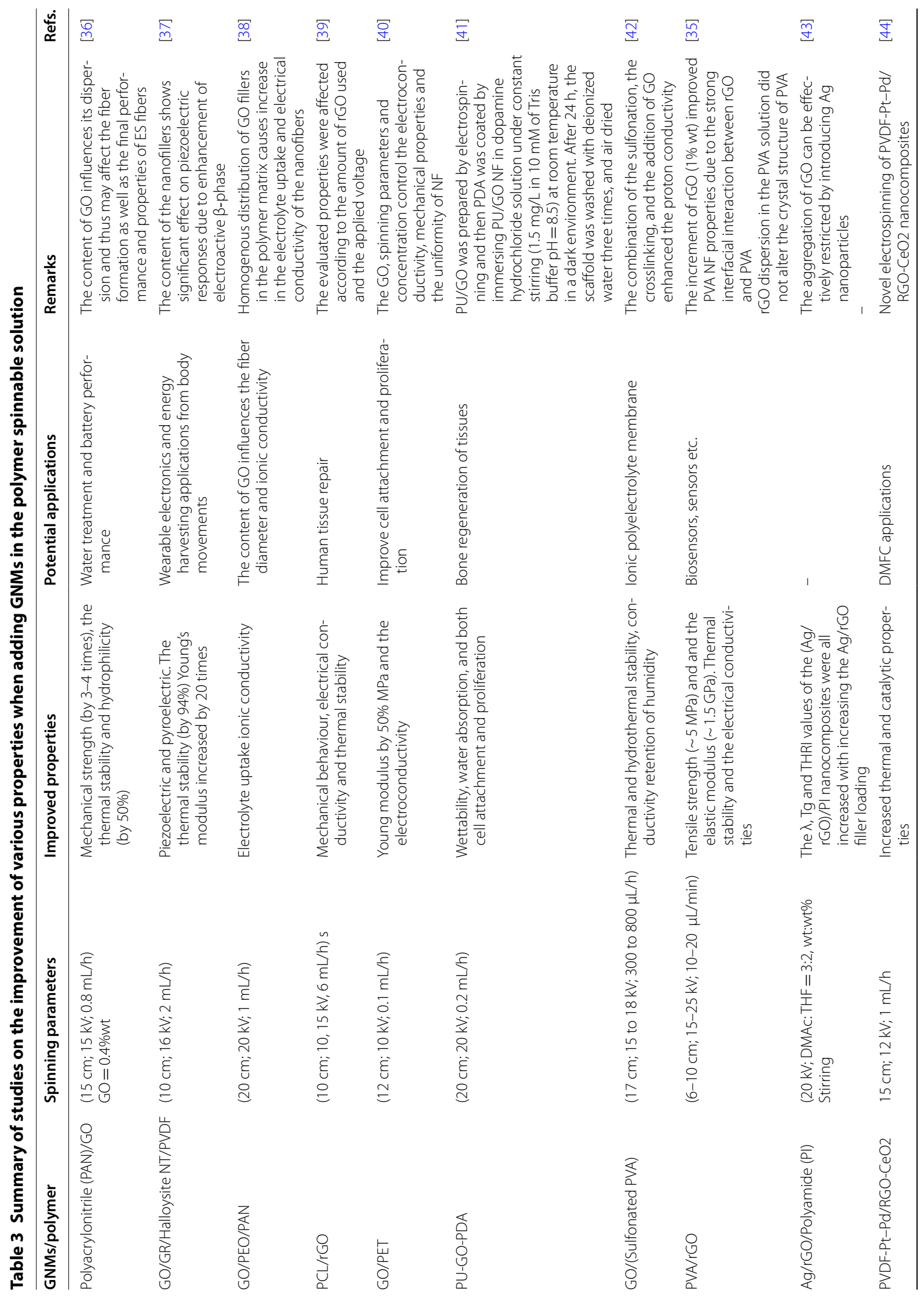




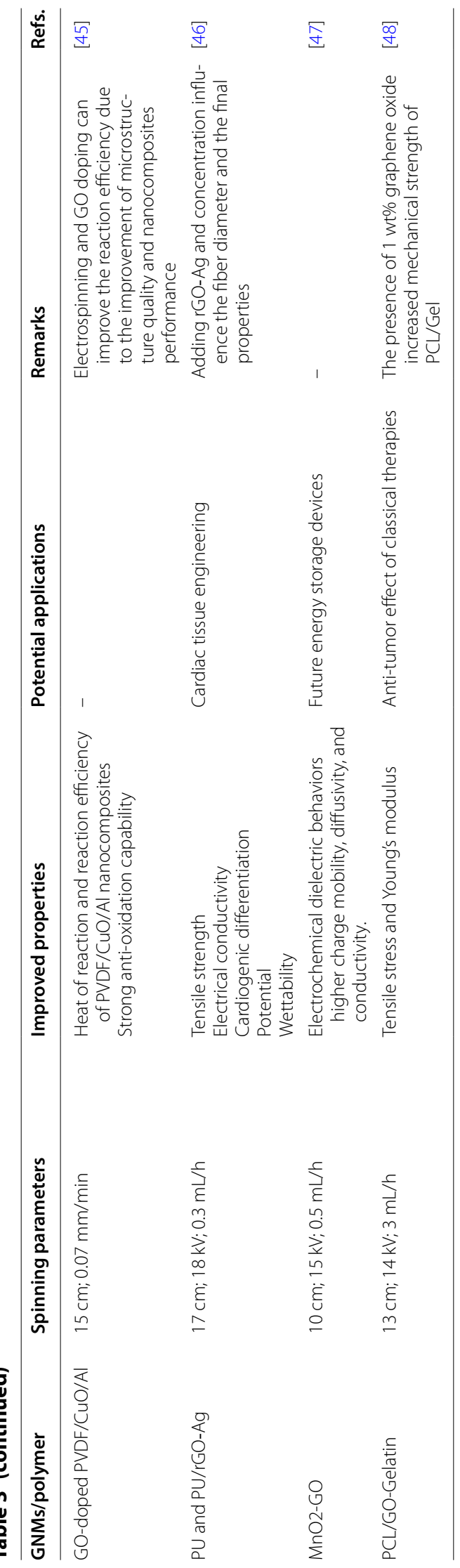




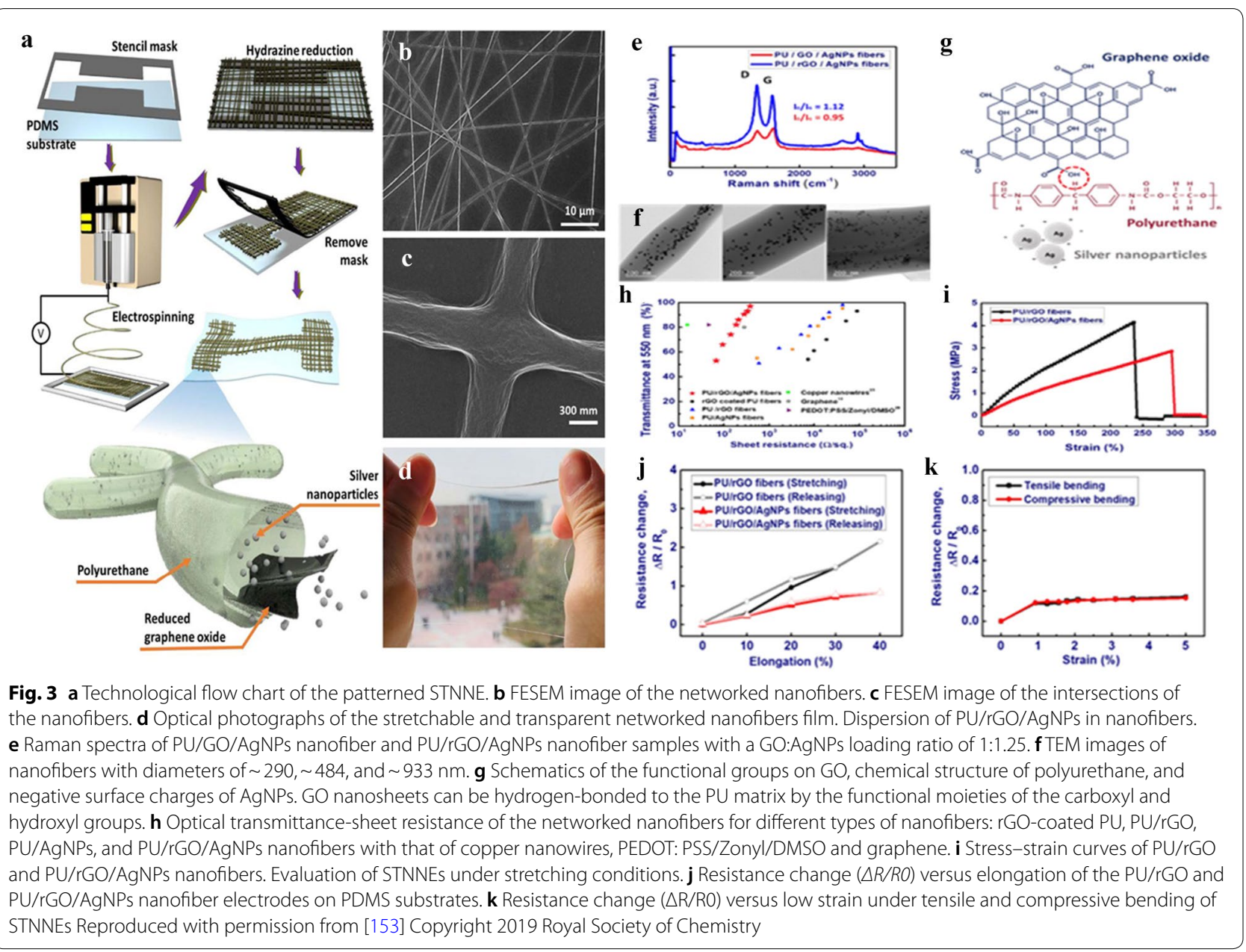

in PVDF/GO fibers and the charge separation induced by the fluorine which acts as a polarization center. Additional file 1: Figure $\mathrm{S} 2 \mathrm{a}$, b show the piezoelectric response using PFM. Additional file 1: Figure S2c, d show that, adding GO and GOF provided significantly enhanced dielectric constant of PVDF composites due to the fluorine groups that could trap and accumulate large electrons at the interface. Additional file 1: Figure S2e depicts the P-E loops for PVDF and GO, GOF and GOOCH.

\section{Electrochemical biosensors based electrospun GNMs nanocomposites}

Biosensors are analytical devices capable of transferring the response of bio-tests into current signals which comprises two parts, biological detection part and the transduction part. The former is the main part of biosensors which compose of biosensing element (e.g. aptamer, enzyme) that provides selective identification of the biotests and converts this detection into processable (current) signals by redox reaction. The latter serves as a platform to transforms the resulting signal from the biomolecule (bioreceptor)-analytes interactions as a current signal to a receiving system for further measurement and quantification. Recently, incorporating GNMs into ESNF to create electrochemical sensors is gaining a wide consideration from researchers mainly because ES GNMs provide a remarkably improved sensitivity and low detection limit caused by their electrochemical probable space, low charge conformation, well-demarcated redox crests, electrocatalytic properties and electron transfer kinetics [197]. Additionally, GNMs possess other excellent characteristics such as high surface area, low-cost, and mass electron transfer ability [155]. In terms of GNMs NFs biosensors, ESNFs serves as the upholder to GNMs as well as the bioreceptors because they possess no reactive ability and thus, do not involve in the detection and transduction parts. Meanwhile, the GNMs act as the detection and transduction parts due to their high adsorption and reactive and abilities for target analytes via chemical bonding or physical adsorption. Highly and uniformly 


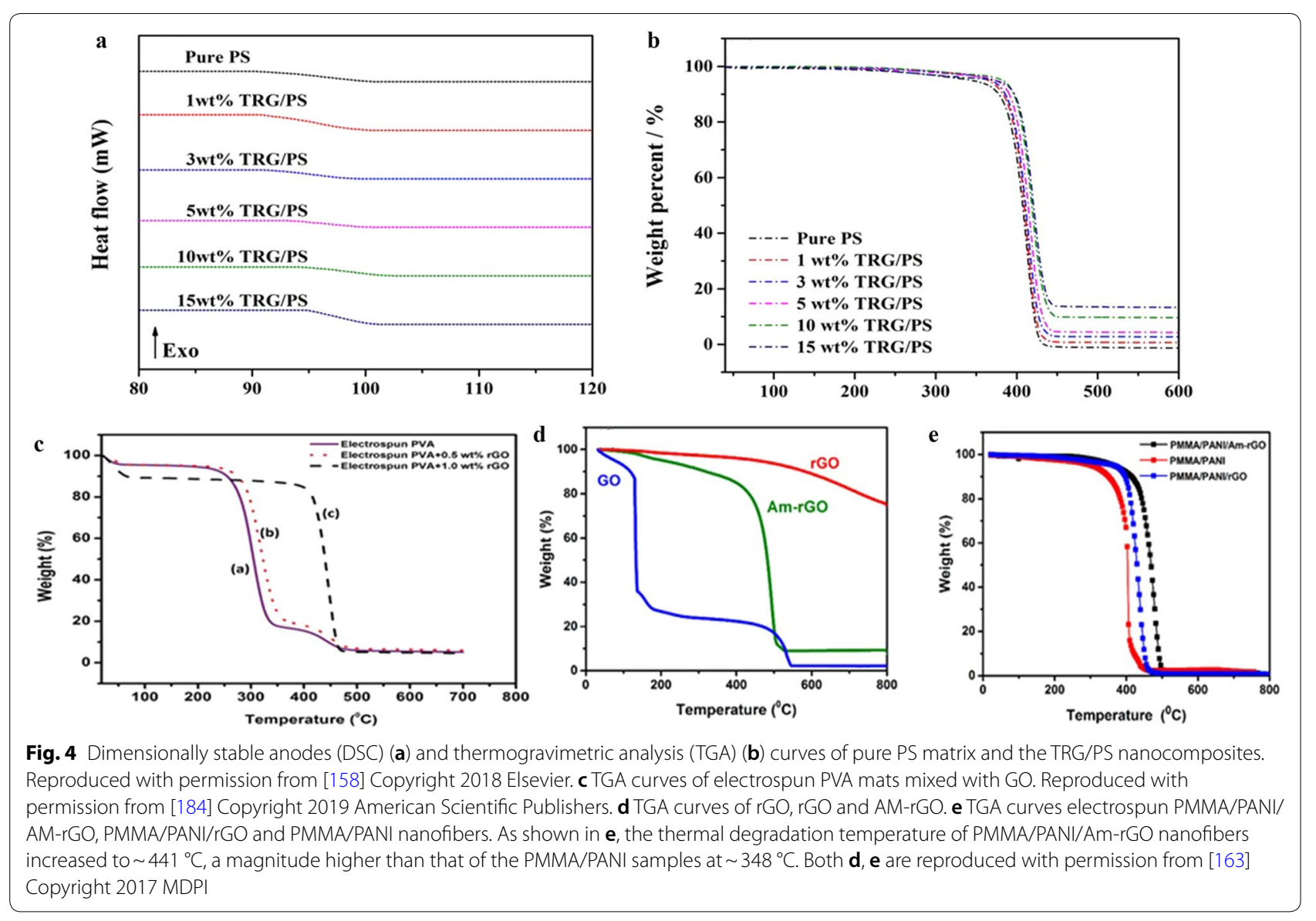

dispersed and distributed GNMs into ESNFs improves the reactivity, speeds up the both adsorption or releases mechanisms and provides large number of GNMs active sites to act as immobilization matrices for bioreceptors (biorecognition elements) in electrochemical biosensors which enhances the electron transfer rate between the biomolecule and the transducer as well as help to preserve their bioactivity on the sensing electrodes [198]. Furthermore, the morphology of ES GNMs NF (porous, core-shell and hollow) contains channels and pores that allows a fluid (e.g. biochemical or chemical species, solvents, gas, etc.) to pass through with minimally reduced mass resistance thereby increasing the analyte diffusion toward the surface of the electrode and provide accurate and ultrasensitive detections [199, 200]. Table 4 shows the summary of ES GNMs and polymer NF composites for sensing applications.

Electrospinning is a facile and convenient technique to fabricate nanofibers based biosensors from a wide range of macroporous and mesoporous materials [132]. Electrospinning endow the polymer nanofibers with predictable and controlled pore geometries, desired diameter and thickness, confirmations and chemical functionalities which benefit the fabrication of novel nanostructure materials with biosensing capabilities [199]. Moreover, the opportunity is to modify and functionalize ES NFs on a largescale allows this technique to meet a vast range of sensing requirements over other methods mainly due to the high surface area, high porosity, control of the chemical compositions and the direct electrospinning on a conductive electrode [201]. ESNFs can be functionalized by incorporating GNMs during electrospinning or after electrospinning onto the surface of the as-prepared nanofibers to enhance the essential properties for fabricating electrochemical biosensors (electrical conductivity, electrochemical properties, electron transfer, catalytic reactions). Due to their high specific surface area and high porosity, ESNFs provides immobilizations sites and thus can bind to biorecognition elements through EDC/NHS chemistry enabling biorecognition-analytes interface and enhance the current response for the test biomolecules.

Zhang et al. [202] reported a facile fabrication of a highly sensitive, efficient, stable, and reproducible electrochemical biosensor for $\mathrm{H}_{2} \mathrm{O}_{2}$ detection by electrospinning PVA with GQDs onto glass carbon electrode 
Table 4 Summary of studies on ES GNMs and polymer NF composites for biosensing and sensing applications

\begin{tabular}{|c|c|c|c|c|c|}
\hline GNMs/Polymer & Spinning parameters & Limit of detection limits & Biomolecule & Target & References \\
\hline rGO/PVP/Chi & $(12 \mathrm{~cm} ; 22 \mathrm{kV} ; 0.5 \mathrm{~mL} / \mathrm{h})$ & $0.15 \mathrm{pmol} \mathrm{L}^{-1}$ & Laccase enzyme & EE2 & {$[162]$} \\
\hline GQDs/PVP & $(10 \mathrm{~cm} ; 20 \mathrm{kV} ; 0.5 \mathrm{~mL} / \mathrm{l})$ & $12 \mu \mathrm{M}$ & - & Glucose & [203] \\
\hline $\begin{array}{l}\text { GO/PAN heat treat- } \\
\text { ment }>\text { CNT/RGO }\end{array}$ & $15 \mathrm{~cm} ; 15 \mathrm{kV} ; 1.6 \mathrm{~mL} / \mathrm{h}$ & & - & $\begin{array}{l}\text { Electrochemical } \\
\text { detection of } \\
\text { L-cysteine }\end{array}$ & [172] \\
\hline PAN/GO & $\begin{array}{l}15 \mathrm{~cm} ; 10 \mathrm{kV} ; 0.5 \mathrm{~mL} / \mathrm{h} \\
\mathrm{DMF} \text {, sonication and stirring }\end{array}$ & & $\begin{array}{l}0.25 \text { for lidocaine and } \\
0.5 \text { for prilocaine } \\
2.5 \text { for } 2,6 \text {-xylidine } \\
1.25 \text { for o-toluidine }\end{array}$ & $\begin{array}{l}\text { Extraction of } \\
\text { lidocaine and } \\
\text { prilocaine }\end{array}$ & [204] \\
\hline
\end{tabular}

$\mathbf{a}$

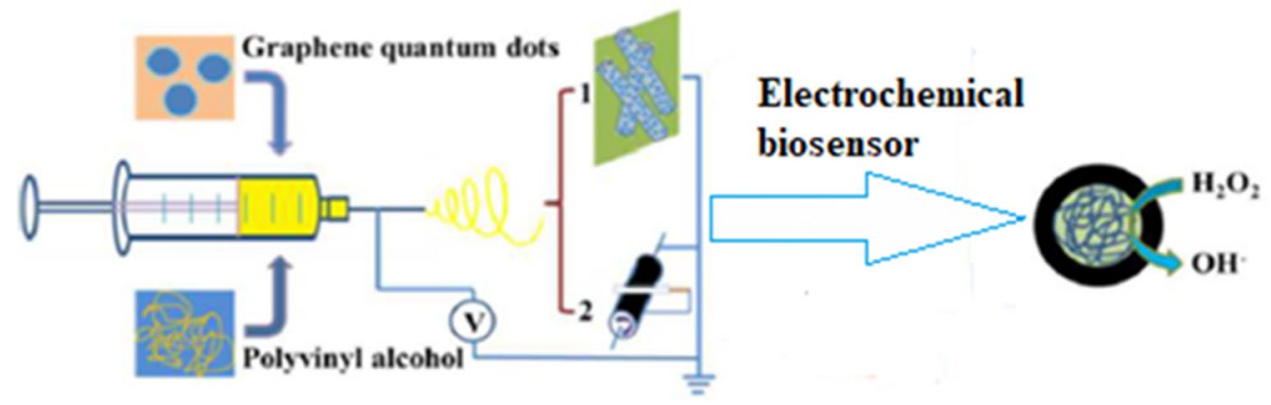

b
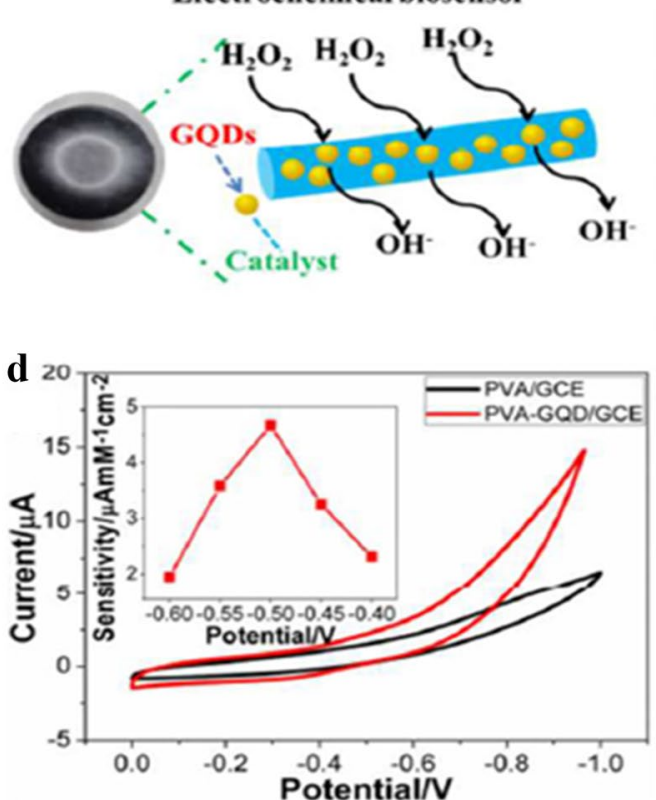

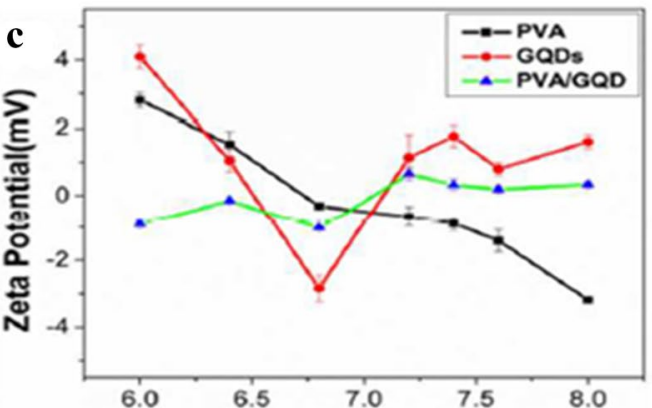

e

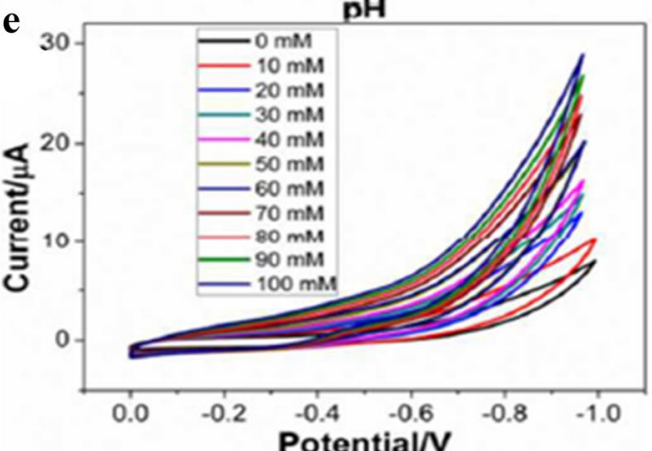

Fig. 5 a Schematic presentation of electrospinning for producing PVA/GQD onto GCE for electrochemical biosensing and catalyzing of $\mathrm{H}_{2} \mathrm{O}_{2}$, b the possible detection mechanism, $\mathbf{c}$ Zeta potentials of GQDs, PVA, and PVA/GQD nanofibrous membranes at varied pH, $\mathbf{d}$ CVs of GCEs modified with PVA and PVA/GQD nanofibrous membranes, sensitivity of the biosensor at different potentials (inset), e CVs of the PVA/GQD nanofibrous membranes modified GCE 0.1 M PBS with different addition of $\mathrm{H}_{2} \mathrm{O}_{2}$ (Reproduced with permission from [202], Copywrite 2015 Royal Society of Chemistry) 
(GCE) (Fig. 5). GQDs were added into $0.5 \mathrm{~g}$ PVA followed by ultrasonication for $2 \mathrm{~h}$ and incubation for $10 \mathrm{~h}$. The final concentration of GQDs was $10-50 \mathrm{mM}$ and the obtained homogeneous solution was used for electrospinning PVA/GQDs nanofibrous membrane. The electrospinning parameters were set to $15 \mathrm{kV}$ applied voltage, $12 \mathrm{~cm}$ receiving distance, and $0.3-0.5 \mathrm{~mL} / \mathrm{h}$ flow rate. The ES GQDs electrochemical biosensor showed a linear detection range of $0.1-200 \mathrm{mM}$ and a detection limit of $0.53 \mu \mathrm{M}$. It was found that, GQDs can replace the traditional semiconductor QDs and preserve the electrochemical properties of carbon materials.

Pavinatto et al. [162] proposed a novel ultrasensitive and highly selective electrochemical biosensor based on polyvinylpyrrolidone/chitosan/reduced graphene oxide ES NFs for $17 \alpha$-Ethinylestradiol (EE2) detection. The spinnable solution was prepared by dispersing $4 \% \mathrm{w} / \mathrm{v}$ of PVP in ethanol and $1.2 \% \mathrm{w} / \mathrm{v}$ chitosan in acetic acid/ water $(9: 1 \mathrm{w} / \mathrm{v})$. Both solutions were mixed and stirred overnight at room temperature before adding 0.035\% $\mathrm{w} / \mathrm{v}$ of $\mathrm{rGO}$ which was dissolved in ethanol. The spinning parameters were $22 \mathrm{kV}$ applied voltage, $12 \mathrm{~cm}$ receiving distance, and $0.5 \mathrm{~mL} / \mathrm{h}$ feed rate. The nanofiber composite was deposited on FTO electrodes attached to a metallic collector with a deposition time of $2.5 \mathrm{~h}$. Upon the characterization of the fibers and prior to immobilizing Laccase enzyme, the fabricated PVP/Chi/rGO ESNFs were treated with glutaraldehyde solution and subsequent crosslinking solution was applied to the nanofiber composite to activate the amine $\left(-\mathrm{NH}_{2}\right)$ and the hydroxyl $(-\mathrm{OH})$ groups from chitosan and graphene sheets, respectively. Covalent bonding was utilized to immobilize the Laccase enzyme to the nanofiber composite through $\mathrm{NH}_{2}$ groups of Laccase enzyme and the activated groups from the nanofiber composite. The PVP/Chi/rGO/Laccase electrode was used to detect EE2. It was revealed that, the integration of Chi and PVP with rGO increased the charge transfer leading to the excellent electrochemical biosensing properties. Figure $6 \mathrm{a}$ reveals the formation of the electrochemical biosensor in terms of coating Laccase enzyme into the FTO/PVP/Chi/rGO nanofiber composite and the $\mathrm{CV}$, electrochemical impedance spectroscopy (EIS) and amperometry measurements are shown in Fig. 6b-d respectively. Recently, Nathani and Sharma [129] demonstrated the use of electrospun mesoporous poly (Styrene-Block-methylmethacrylate) nanofibers (ES PS-b-PMMA NF) to enhance the analytical performance of electrochemical biosensor by exploiting the effect of porosity and surface area on the sensing ability of electropsun nanofibers. EDC-NHS chemistry was chosen to biofunctionalized the PS-b-PMMA NFs and the redox response was utilized to study the presence of the carboxyl group. The fabricated electrochemical porous biosensor showed an increase of the sensitivity by 2.7 -fold, a detection range of $10 \mathrm{fM}-10 \mathrm{nM}$ and a detection limit of $0.37 \mathrm{fM}$ along with good selectivity. Figure $6 \mathrm{e}$ shows the voltammetry results of the developed electrochemical biosensor.

\section{Future outlook}

Electrospinning has become one of the most vital techniques to fabricate the functional nanofiber composites with the desired structure and compositions. However, several challenges hinder the transition of electrospinning method from the laboratory scale to industrial scale production such as spinneret configuration, rheology, solution concentration, electric field intensity and distribution, humidity and temperature, flowrate, receiving distance and collector geometry. These parameters could also influence the reproducibility of ESNFs over time and in different locations. On the other hand, the integration of GNMs and polymer nanofibers using electrospinning has proved to be an excellent strategy to fabricate efficient sensing materials-taking the dual advantages of the wonderful functional properties of GNMs and electrospun polymeric nanofibers. However, to attain high-performance electrochemical biosensors, some challenges should be circumvented such as to increase GNMs contents without agglomeration or aggregation to and to increase the immobilization sites for bio-tests molecules. Additionally, to optimize the synergistic effects between graphene and other nanomaterials as well as to improve the electrocatalytic efficiency for electrochemical sensors are mandatory. There are appropriate modification and fabrication of GNMs and polymer nanofibers for biosensor design via electrospinning which are pre- and post-processing methods. The former involves mixing the polymers with GNMs before electrospinning which is a universal and efficient method to fabricate ES GNMs nanostructures for biosensors with enhanced stability, physical and chemical properties, reusability, and long-term storage stability. The latter involves coating or decorating the GNMs onto the surface of as-prepared nanofibers for immediate interface with biomolecules which in turn leads to the enhanced performance of electrochemical biosensors. The pre-processing methods show more superiorities for biosensing performance; however, they require few harsh conditions like violent stirring, in situ growth of GNMs and/or the use of complicated device such as coaxial electrospinning. Additional challenges of pre-processing methods include the dispersion, alignment and the appropriate loading of GNMs with the polymer matrices. Furthermore, more studies are required to control the synergistic effect of GNMs and their interactions with the polymer matrices during the electrospinning process to ensure uniformity 


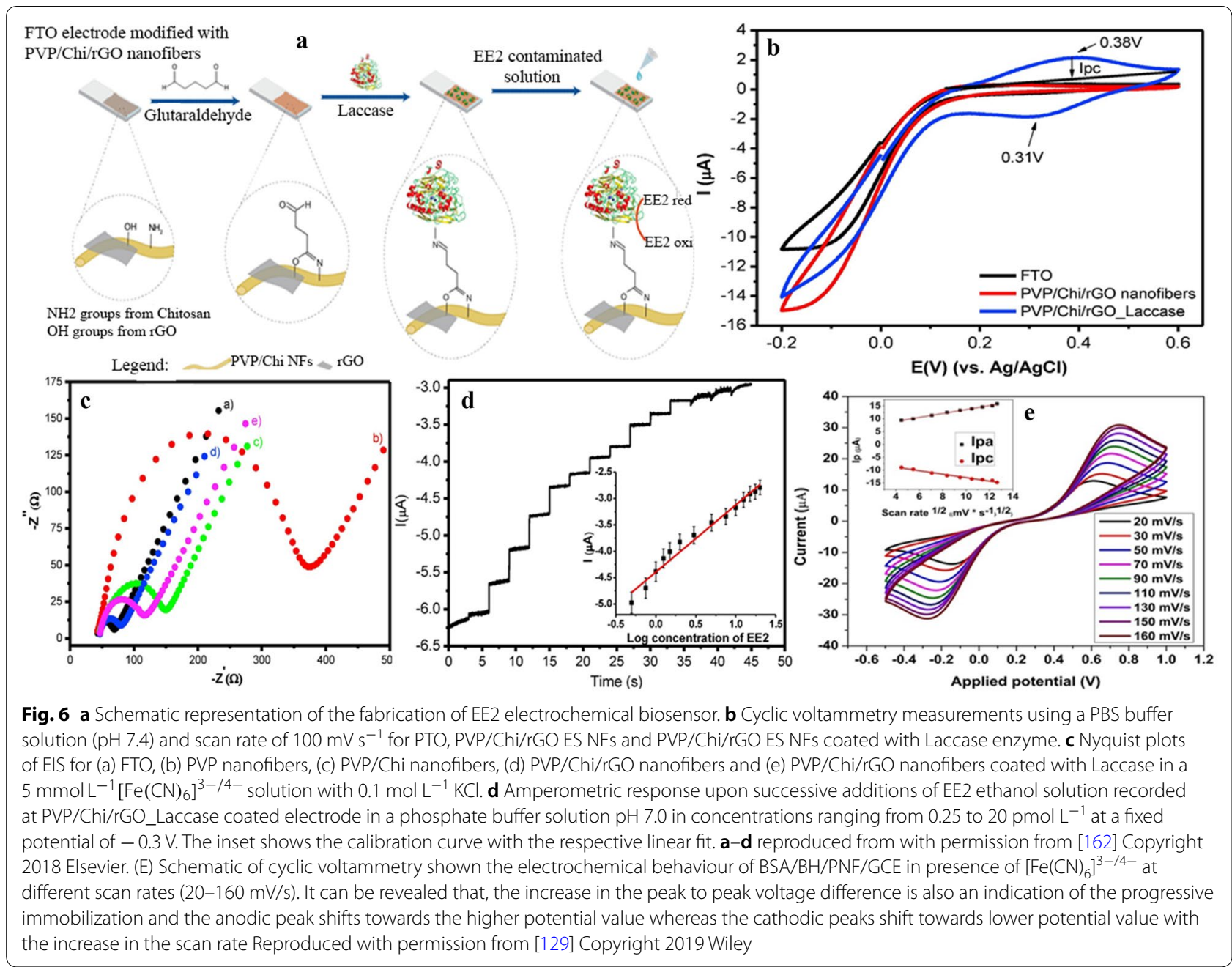

and dispersity of GNMs. The post-processing methods typically have higher efficiency of utilizing GNMs directly for biosensing applications due to the possibility to decorate a large surface area of as-prepared nanofibers with GNMs thus maximizing the potential interface between GNMs and biomolecules to facilitating ultrasensitive detection of bio-tested analytes. The major challenge of post-processing methods lies on their ability to establish accurate interactions between the GNMs and the polymer nanofibers because GNMs cannot easily integrated with the as-prepared nanofibers. Therefore, more studies are required to optimize the coating or to develop novel coating strategy of GNMs onto electrospun nanofibers to increase the interfacial bonding between GNMs and electrospun nanofibers. Recently, [205] reported a facile strategy to realize a strong connection between multi carbon nanotubes (MWCNTs) and poly (vinylidene fluoride-co-hexafluoropropylene) ESNFs via thermal-induced welding. Ren et al. [206] reported an effective strategy to improve the structural integrity between CVD graphene and polyacrylonitrile (PAN) ESNFs via annealing process to fabricate a transparent sensor with enhanced conductivity, mechanical strength, sensitivity, stability and a low detection limit.

This review elucidated the recent achievements on electrospun design of functional nanostructures for biosensing applications by exploiting the remarkable properties of GNMs using pre-processing and post processing methods. It can be concluded that, the appropriate modification of GNMs with surface functional groups (e.g. reduction of GO to $\mathrm{rGO}$ and or adding additives) improve their dispersion within the polymer matrices thereby enhancing the electrical conductivity, thermal stability, electrochemical and mechanical properties of the electrospun nanostructured composites. Additionally, the modification of electrospun nanofibers as well as optimizing electrospinning design to 
fabricate porous, core-shell and hollow nanostructures increase the surface area and therefore the immobilization sites for biomolecules increases. This overview highlighted the recent progress on graphene fabrication materials, the remarkable role of GNMs to construct next generation electro-sensing devices and the importance of electrospinning designs of nanostructured composites towards bridging laboratory set-up to the industry.

\section{Supplementary information}

Supplementary information accompanies this paper at https://doi. org/10.1186/s40580-020-00237-4.

Additional file 1: Figure S1. Cyclic voltammetry curves of $(\mathbf{A})$ polyaniline (PANI)-coated nanofibers (NP3) and (B) PANI/graphene-coated nanofibers (NP3G2). Schematic representation of the charge/discharge curves of (C) polyaniline (PANI)-coated nanofibers (NP3) and (D) PANI/graphene-coated nanofibers (NP3G2) Ref. [31]. Figure S2. Piezoelectric force microscopy (PFM) amplitude vs dc voltage (voltage varying from -12 to $12 \mathrm{~V}$ ) hysteresis loops for (a) PVDF/GOCOOH and (b) PVDF/GOF. Frequency dependence of (c) dielectric constant and (d) dielectric loss for PVDF/GO, PVDF/GOCOOH, and PVDF/GOF composites. (e) schematic representing the $P$ - E loops for PVDF/GO, PVDF/GOCOOH, and PVDF/GOF at room temperature. (a-e) are obtained from Ref [24] Copy Right ACS.

\section{Abbreviations}

CV: Cyclic voltammetry; CVD: Chemical vapor deposition; CNTs: Carbon nanotubes; DMF: Dimethylformamide; EIS: Electrochemical impedance spectroscopy; ESNFs: Electrospun nanofibers; GNMs: Graphene-based nanomaterials; GO: Graphene oxide; rGO: Reduced graphene oxide; GQD: Graphene quantum dots; PAN: Polyacrylonitrile; PANI: Polyaniline; PS: Polystyrene; PU: Polyurethane; PVA: Poly (vinyl alcohol); PVDF: Polyvinylidene fluoride; PVP: Poly (vinyl pyrrolidone); SEM: Scanning electron microscope.

\section{Acknowledgements}

The authors gratefully acknowledged UTP for the research facilities provided to conduct experiments.

\section{Authors' contributions}

AMAD, SCBG, and MSMS wrote the manuscript. All authors reviewed the final manuscript. All authors read and approved the final manuscript.

\section{Funding}

This work is financially supported by University Research Internal Fund (URIF) with Grant No.: 015LB0-020.

\section{Availability of data and materials}

All data and material will be made available upon request.

\section{Competing interests}

The authors declare that they have no known competing financial interests that could have appeared to influence the work reported in this paper.

\footnotetext{
Author details

${ }^{1}$ Department of Fundamental \& Applied Sciences, Universiti Teknologi PETRONAS, 32610 Seri Iskandar, Perak Darul Ridzuan, Malaysia. ${ }^{2}$ Centre of Innovative Nanostructure \& Nanodevices (COINN), Universiti Teknologi PETRONAS, 32610 Seri Iskandar, Perak Darul Ridzuan, Malaysia. ${ }^{3}$ School of Bioprocess Engineering, Universiti Malaysia Perlis, 02600 Arau, Perlis, Malaysia. ${ }^{4}$ Institute of Nano Electronic Engineering, Universiti Malaysia Perlis, 01000 Kangar, Perlis, Malaysia. ${ }^{5}$ Department of Mechanical Engineering , Universiti Teknologi PETRONAS, 32610, Seri Iskandar, Perak Darul Ridzuan, Malaysia.
}

Received: 27 December 2019 Accepted: 7 July 2020

Published online: 10 August 2020

\section{References}

1. S.K. Krishnan, E. Singh, P. Singh, M. Meyyappan, H.S. Nalwa, A review on graphene-based nanocomposites for electrochemical and fluorescent biosensors. RSC Adv. 9, 8778-8781 (2019). https://doi.org/10.1039/ c8ra09577a

2. N. Wongkaew, M. Simsek, C. Griesche, A.J. Baeumner, Functional nanomaterials and nanostructures enhancing electrochemical biosensors and lab-on-a-chip performances: recent progress, applications, and future perspective. Chem. Rev. 119, 120-194 (2019). https://doi. org/10.1021/acs.chemrev.8b00172

3. M.H. Asif, A. Razaq, N. Akbar, B. Danielsson, I. Sultana, Facile synthesis of multisegment Au/Ni/Au nanowire for high performance electrochemical glucose sensor. Mater. Res. Express. 6, 95028 (2019)

4. R. Asmatulu, Z. Veisi, M.N. Uddin, A. Mahapatro, Highly sensitive and reliable electrospun polyaniline nanofiber based biosensor as a robust platform for COX-2 enzyme detections. Fibers Polym. 20, 966-974 (2019). https://doi.org/10.1007/s12221-019-1096-X

5. Y. Niu, H. Xie, G. Luo, W. Weng, C. Ruan, G. Li, W. Sun, Electrochemical performance of myoglobin based on $\mathrm{TiO}_{2}$-doped carbon nanofiber decorated electrode and its applications in biosensing. RSC Adv. 9 , 4480-4487 (2019). https://doi.org/10.1039/c8ra07910b

6. R. Patel, P. Zaveri, A. Mukherjee, P.K. Agarwal, P. More, N.S. Munshi, Development of fluorescent protein-based biosensing strains: a new tool for the detection of aromatic hydrocarbon pollutants in the environment. Ecotoxicol. Environ. Saf. 182, 109450 (2019). https://doi.org/10.1016/j. ecoenv.2019.109450

7. M. Dhawane, A. Deshpande, R. Jain, P. Dandekar, Colorimetric pointof-care detection of cholesterol using chitosan nanofibers. Sensors Actuators, B Chem. 281, 72-79 (2019). https://doi.org/10.1016/j. snb.2018.10.060

8. F. Hassan, C. Gentry-weeks, M. Reynolds, Y.V. Li, Study on microstructure and mechanical properties of polydiacetylene composite biosensors. J. Appl. Polym. Sci. 47877, 1-14 (2019). https://doi.org/10.1002/ app.47877

9. P. Mengarda, F.A.L. Dias, J.V.C. Peixoto, R. Osiecki, M.F. Bergamini, L.H. Marcolino, Determination of lactate levels in biological fluids using a disposable ion-selective potentiometric sensor based on polypyrrole films. Sensors Actuators B Chem. 126, 663 (2019)

10. S. Dantism, D. Röhlen, T. Selmer, T. Wagner, P. Wagner, M.J. Schöning, Quantitative differential monitoring of the metabolic activity of Corynebacterium glutamicum cultures utilizing a light-addressable potentiometric sensor system. Biosens. Bioelectron. 139, 111332 (2019)

11. P. Vizzini, M. Braidot, J. Vidic, M. Manzano, Electrochemical and optical biosensors for the detection of campylobacter and listeria: an update look. Micromachines. 10, 500 (2019)

12. C. Banbury, J.J.S. Rickard, S. Mahajan, P. GoldbergOppenheimer, Tuneable metamaterial-like platforms for surface-enhanced raman scattering via three-dimensional block co-polymer-based nanoarchitectures. ACS Appl. Mater. Interfaces. 11, 14437-14444 (2019)

13. Y. Jiang, D.-W. Sun, H. Pu, Q. Wei, Ultrasensitive analysis of kanamycin residue in milk by SERS-based aptasensor. Talanta 197, 151-158 (2019)

14. Z. Rezaei, M. Mahmoudifard, Pivotal role of electrospun nanofibers in microfluidic diagnostic systems - a review. J. Mater. Chem. B. 7, 4602-4619 (2019). https://doi.org/10.1039/c9tb00682f

15. J. Zhang, F. Zhang, J. Song, L. Liu, Y. Si, J. Yu, B. Ding, Electrospun flexible nanofibrous membranes for oil/water separation. J. Mater. Chem. A. 7, 20075-20102 (2019). https://doi.org/10.1039/c9ta07296a

16. T. Tite, E.A. Chiticaru, J.S. Burns, M. Ioniță, Impact of nano-morphology, lattice defects and conductivity on the performance of graphene based electrochemical biosensors. J. Nanobiotechnol. 17, 1-22 (2019). https://doi.org/10.1186/s12951-019-0535-6

17. G. Park, S. Kim, S. Chae, H. Han, T.H. Le, K.S. Yang, M. Chang, H. Kim, H. Yoon, Combining SWNT and graphene in polymer nanofibers: a route to unique carbon precursors for electrochemical capacitor electrodes. Langmuir 35, 3077-3086 (2019). https://doi.org/10.1021/acs.langm uir.8b03766 
18. E. Correa, M.E. Moncada, O.D. Gutiérrez, C.A. Vargas, V.H. Zapata, Characterization of polycaprolactone/rGO nanocomposite scaffolds obtained by electrospinning. Mater. Sci. Eng. C 103, 109773 (2019). https://doi. org/10.1016/j.msec.2019.109773

19. B. SuganyaBharathi, T. Stalin, Cerium oxide and peppermint oil loaded polyethylene oxide/graphene oxide electrospun nanofibrous mats as antibacterial wound dressings. Mater. Today Commun. 21, 100664 (2019). https://doi.org/10.1016/j.mtcomm.2019.100664

20. D.G. Prajapati, B. Kandasubramanian, Progress in the development of intrinsically conducting polymer composites as biosensors. Macromol. Chem. Phys. 220, 1-26 (2019). https://doi.org/10.1002/macp.20180 0561

21. J. Avossa, R. Paolesse, C. Di Natale, E. Zampetti, G. Bertoni, F. De Cesare, G. Scarascia-Mugnozza, A. Macagnano, Electrospinning of polystyrene/ polyhydroxybutyrate nanofibers doped with porphyrin and graphene for chemiresistor gas sensors. Nanomaterials. 9, 280 (2019). https://doi org/10.3390/nano9020280

22. J.-H. Lee, S. Park, J.W. Choi, Electrical property of graphene and its application to electrochemical biosensing. Nanomaterials. 9, 297 (2019). https://doi.org/10.3390/nano9020297

23. J. Sengupta, C.M. Hussain, Graphene and its derivatives for analytical lab on chip platforms. TrAC 114, 326-337 (2019). https://doi.org/10.1016/j. trac.2019.03.015

24. S. Muniandy, S.J. Teh, K.L. Thong, A. Thiha, I.J. Dinshaw, C.W. Lai, F. Ibrahim, B.F. Leo, Carbon nanomaterial-based electrochemical biosensors for foodborne bacterial detection. Crit. Rev. Anal. Chem. (2019). https:// doi.org/10.1080/10408347.2018.1561243

25. Y. Song, Y. Luo, C. Zhu, H. Li, D. Du, Y. Lin, Recent advances in electrochemical biosensors based on graphene two-dimensional nanomaterials. Biosens. Bioelectron. 76, 195-212 (2016). https://doi.org/10.1016/j. bios.2015.07.002

26. A. Liang, X. Jiang, X. Hong, Y. Jiang, Z. Shao, D. Zhu, Recent developments concerning the dispersion methods and mechanisms of graphene. Coatings. 8, 33 (2018). https://doi.org/10.3390/coatings8010033

27. Y. Guo, X. Yang, K. Ruan, J. Kong, M. Dong, J. Zhang, J. Gu, Z. Guo, Reduced graphene oxide heterostructured silver nanoparticles significantly enhanced thermal conductivities in hot-pressed electrospun polyimide nanocomposites. ACS Appl. Mater. Interfaces. 11, 2546525473 (2019). https://doi.org/10.1021/acsami.9b10161

28. L.A. Mercante, V.P. Scagion, F.L. Migliorini, L.H.C. Mattoso, D.S. Correa, Electrospinning-based (bio)sensors for food and agricultural applications: a review. TrAC 91, 91-103 (2017). https://doi.org/10.1016/j. trac.2017.04.004

29. M. Zhang, Y. Li, Z. Su, G. Wei, Recent advances in the synthesis and applications of graphene-polymer nanocomposites. Polym. Chem. 6 , 6107-6124 (2015)

30. M.M. Abdel-Mottaleb, A. Khalil, S. Karim, T.A. Osman, A. Khattab, High performance of PAN/GO-ZnO composite nanofibers for photocatalytic degradation under visible irradiation. J. Mech. Behav. Biomed. Mater. 96 118-124 (2019)

31. J.K.Y. Lee, N. Chen, S. Peng, L. Li, L. Tian, N. Thakor, S. Ramakrishna, Polymer-based composites by electrospinning: preparation and functionalization with nanocarbons. Prog. Polym. Sci. 86, 40-84 (2018)

32. S. DemiroğluMustafov, A.K. Mohanty, M. Misra, M.Ö. Seydibeyoğlu, Fabrication of conductive Lignin/PAN carbon nanofiber with enhanced graphene for the modified electrode. Carbon N. Y. 147, 262-275 (2019). https://doi.org/10.1016/j.carbon.2019.02.058

33. M.E. Darzi, S.I. Golestaneh, M. Kamali, G. Karimi, Thermal and electrical performance analysis of co-electrospun-electrosprayed PCM nanofiber composites in the presence of graphene and carbon fiber powder. Renew. Energy. 135, 719-728 (2019). https://doi.org/10.1016/j.renen e.2018.12.028

34. S. Jiang, Y. Chen, G. Duan, C. Mei, A. Greiner, S. Agarwal, Electrospun nanofiber reinforced composites: a review. Polym. Chem. 9, 2685-2720 (2018). https://doi.org/10.1039/c8py00378e

35. X. Lu, M. Li, H. Wang, C. Wang, Advanced electrospun nanomaterials for highly efficient electrocatalysis. Inorg. Chem. Front. (2019). https ://doi.org/10.1039/c9qi00799g

36. Q. Liu, Z. Chen, X. Pei, C. Guo, K. Teng, Y. Hu, Z. Xu, X. Qian, Review: applications, effects and the prospects for electrospun nanofibrous mats in membrane separation. J. Mater. Sci. (2019). https://doi. org/10.1007/s10853-019-04012-7

37. D.H. Reneker, A.L. Yarin, Electrospinning jets and polymer nanofibers. Polymer (Guildf). 49, 2387-2425 (2008)

38. S.S. Ray, S.-S. Chen, C.-W. Li, N.C. Nguyen, H.T. Nguyen, A comprehensive review: electrospinning technique for fabrication and surface modification of membranes for water treatment application. RSC Adv. 6, 85495-85514 (2016). https://doi.org/10.1039/C6RA14952A

39. A. Haider, S. Haider, I.-K. Kang, A comprehensive review summarizing the effect of electrospinning parameters and potential applications of nanofibers in biomedical and biotechnology. Arab. J. Chem. 11, $1165-1188$ (2018)

40. J. Xue, T. Wu, Y. Dai, Y. Xia, U. States, Electrospinning and electrospun nano fibers: methods, materials, and applications. Chem. Rev. (2019). https://doi.org/10.1021/acs.chemrev.8b00593

41. C. Wang, J. Wang, L. Zeng, Z. Qiao, X. Liu, H. Liu, J. Zhang, J. Ding, Fabrication of electrospun polymer nanofibers with diverse morphologies. Molecules (2019). https://doi.org/10.3390/molecules24050834

42. L. Wang, G. Yang, S. Peng, J. Wang, W. Yan, S. Ramakrishna, Onedimensional nanomaterials toward electrochemical sodium-ion storage applications via electrospinning. Energy Storage Mater. (2019). https://doi.org/10.1016/j.ensm.2019.09.036

43. Y. Sun, S. Cheng, W. Lu, Y. Wang, P. Zhang, Q. Yao, Electrospun fibers and their application in drug controlled release, biological dressings, tissue repair, and enzyme immobilization. RSC Adv. 9, 25712-25729 (2019). https://doi.org/10.1039/C9RA05012D

44. Y. Huang, J. Song, C. Yang, Y. Long, H. Wu, Scalable manufacturing and applications of nanofibers. Mater. Today 28, 98-113 (2019). https:// doi.org/10.1016/j.mattod.2019.04.018

45. R.K. Mishra, P. Mishra, K. Verma, A. Mondal, R.G. Chaudhary, M.M. Abolhasani, S. Loganathan, Electrospinning production of nanofibrous membranes. Springer Int. Publ. (2018). https://doi.org/10.1007/s1031 1-018-00838-w

46. S. Kumar, K. Chatterjee, Comprehensive review on the use of graphene-based substrates for regenerative medicine and biomedical devices. ACS Appl. Mater. Interfaces. 8, 26431-26457 (2016). https ://doi.org/10.1021/acsami.6b09801

47. Y.-C. Kong, P.-R. Wu, J.-W. Dong, H.-L. Ding, Z. Liu, Z.-L. Cheng, Oxalic acid assisted expansion-reduction exfoliation of graphene oxide into graphene nanosheets. Mater. Lett. 231, 51-55 (2018)

48. Y. Che, G. Zhang, Y. Zhang, X. Cao, M. Cao, Y. Yu, H. Dai, J. Yao, Solution-processed graphene phototransistor functionalized with P3HT/ graphene bulk heterojunction. Opt. Commun. 425, 161-165 (2018)

49. S.F. Braga, V.R. Coluci, S.B. Legoas, R. Giro, D.S. Galvão, R.H. Baughman, Structure and dynamics of carbon nanoscrolls. Nano Lett. 4, 881-884 (2004)

50. K.S. Novoselov, A.K. Geim, S.V. Morozov, D. Jiang, Y. Zhang, S.V. Dubonos, I.V. Grigorieva, A.A. Firsov, Electric field effect in atomically thin carbon films. Science (80-) 306, 666-669 (2004)

51. K.I. Bolotin, K.J. Sikes, Z. Jiang, M. Klima, G. Fudenberg, J. Hone, P. Kim, H.L. Stormer, Ultrahigh electron mobility in suspended graphene. Solid State Commun. 146, 351-355 (2008)

52. K.S. Novoselov, A.K. Geim, S. Morozov, D. Jiang, M. Katsnelson, I. Grigorieva, S. Dubonos, A.A. Firsov, Two-dimensional gas of massless Dirac fermions in graphene. Nature. 438, 197 (2005)

53. A.A. Balandin, S. Ghosh, W. Bao, I. Calizo, D. Teweldebrhan, F. Miao, C.N. Lau, Superior thermal conductivity of single-layer graphene. Nano Lett. 8, 902-907 (2008)

54. C. Lee, X. Wei, J.W. Kysar, J. Hone, Measurement of the elastic properties and intrinsic strength of monolayer graphene. Science (80-) 321, 385-388 (2008)

55. Y. Zhu, S. Murali, W. Cai, X. Li, J.W. Suk, J.R. Potts, R.S. Ruoff, Graphene and graphene oxide: synthesis, properties, and applications. Adv. Mater. 22, 3906-3924 (2010). https://doi.org/10.1002/adma.20100 1068

56. X. Zhu, Y. Liu, P. Li, Z. Nie, J. Li, Applications of graphene and its derivatives in intracellular biosensing and bioimaging. Analyst. 141, 4541-4553 (2016). https://doi.org/10.1039/c6an01090c

57. T.P. Dasari Shareena, D. McShan, A.K. Dasmahapatra, P.B. Tchounwou, A review on graphene-based nanomaterials in biomedical applications 
and risks in environment and health. Nano-Micro Lett. 10, 1-34 (2018). https://doi.org/10.1007/s40820-018-0206-4

58. S. Kumar, S.D. Bukkitgar, S. Singhratibha, V. Singh, K.R. Reddy, N.P. Shetti, C. Venkata Reddy, V. Sadhu, S. Naveen, Electrochemical sensors and biosensors based on graphene functionalized with metal oxide nanostructures for healthcare applications. ChemistrySelect. 4, 5322-5337 (2019). https://doi.org/10.1002/slct.201803871

59. D.G. Papageorgiou, I.A. Kinloch, R.J. Young, Mechanical properties of graphene and graphene-based nanocomposites. Prog. Mater Sci. 90, 75-127 (2017). https://doi.org/10.1016/j.pmatsci.2017.07.004

60. S.K. Yadav, J.W. Cho, Functionalized graphene nanoplatelets for enhanced mechanical and thermal properties of polyurethane nanocomposites. Appl. Surf. Sci. 266, 360-367 (2013)

61. W. Tong, Y. Zhang, L. Yu, X. Luan, Q. An, Q. Zhang, F. Lv, P.K. Chu, B. Shen, Z. Zhang, Novel method for the fabrication of flexible film with oriented arrays of graphene in poly (vinylidene fluoride-co-hexafluoropropylene) with low dielectric loss. J. Phys. Chem. C 118, 10567-10573 (2014)

62. M. Yi, Z. Shen, A review on mechanical exfoliation for the scalable production of graphene. J. Mater. Chem. A. 3, 11700-11715 (2015)

63. R.S. Edwards, K.S. Coleman, Graphene synthesis: relationship to applications. Nanoscale. 5, 38-51 (2013)

64. K. Javed, M. Oolo, N. Savest, A. Krumme, A review on graphene-based electrospun conductive nanofibers, supercapacitors, anodes, and cathodes for lithium-ion batteries. Crit. Rev. Solid State Mater. Sci. (2018). https://doi.org/10.1080/10408436.2018.1492367

65. S. Garain, S. Jana, T.K. Sinha, D. Mandal, Design of in situ poled $\mathrm{Ce}^{3+}$-doped electrospun PVDF/graphene composite nanofibers for fabrication of nanopressure sensor and ultrasensitive acoustic nanogenerator. ACS Appl. Mater. Interfaces. 8, $4532-4540$ (2016). https://doi. org/10.1021/acsami.5b11356

66. S. Priyadarsini, S. Mohanty, S. Mukherjee, S. Basu, M. Mishra, Graphene and graphene oxide as nanomaterials for medicine and biology application. J. Nanostruct. Chem. 8, 123-137 (2018). https://doi.org/10.1007/ s40097-018-0265-6

67. I. Khalil, S. Rahmati, N. MuhdJulkapli, W.A. Yehye, Graphene metal nanocomposites-recent progress in electrochemical biosensing applications. J. Ind. Eng. Chem. 59, 425-439 (2018). https://doi.org/10.1016/j. jiec.2017.11.001

68. A.T. Lawal, Graphene-based nano composites and their applications. A review. Biosens. Bioelectron. 141, 111384 (2019). https://doi. org/10.1016/j.bios.2019.111384

69. I.I. Bobrinetskiy, N.Z. Knezevic, Graphene-based biosensors for on-site detection of contaminants in food. Anal. Methods 10, 5061-5070 (2018). https://doi.org/10.1039/c8ay01913d

70. N. Chauhan, T. Maekawa, D.N.S. Kumar, Graphene based biosensorsAccelerating medical diagnostics to new-dimensions. J. Mater. Res. 32 2860-2882 (2017). https://doi.org/10.1557/jmr.2017.91

71. T. Terse-Thakoor, S. Badhulika, A. Mulchandani, Graphene based biosensors for healthcare. J. Mater. Res. 32, 2905-2929 (2017). https://doi. org/10.1557/jmr.2017.175

72. P. Suvarnaphaet, S. Pechprasarn, Graphene-based materials for biosensors: a review. Sensors (2017). https://doi.org/10.3390/s17102161

73. J. Peña-Bahamonde, H.N. Nguyen, S.K. Fanourakis, D.F. Rodrigues, Recent advances in graphene-based biosensor technology with applications in life sciences. J. Nanobiotechnol. 16, 1-17 (2018). https://doi. org/10.1186/s12951-018-0400-z

74. A.T. Lawal, Progress in utilisation of graphene for electrochemical biosensors. Biosens. Bioelectron. 106, 149-178 (2018). https://doi. org/10.1016/j.bios.2018.01.030

75. G. Gnana Kumar, G. Amala, S.M. Gowtham, Recent advancements, key challenges and solutions in non-enzymatic electrochemical glucose sensors based on graphene platforms. RSC Adv. 7, 36949-36976 (2017). https://doi.org/10.1039/c7ra02845h

76. S. Cinti, F. Arduini, Graphene-based screen-printed electrochemical (bio) sensors and their applications: efforts and criticisms. Biosens. Bioelectron. 89, 107-122 (2017)

77. C. Zhang, Z. Zhang, Q. Yang, W. Chen, Graphene-based electrochemical glucose sensors: fabrication and sensing properties. Electroanalysis $\mathbf{3 0}$, 2504-2524 (2018). https://doi.org/10.1002/elan.201800522
78. H. Song, X. Zhang, Y. Liu, Z. Su, Developing graphene-based nanohybrids for electrochemical sensing. Chem. Rec. 19, 534-549 (2019). https ://doi.org/10.1002/tcr.201800084

79. X. Bo, M. Zhou, L. Guo, Electrochemical sensors and biosensors based on less aggregated graphene. Biosens. Bioelectron. 89, 167-186 (2017). https://doi.org/10.1016/j.bios.2016.05.002

80. C.I.L. Justino, A.R. Gomes, A.C. Freitas, A.C. Duarte, T.A.P. Rocha-Santos, Graphene based sensors and biosensors. TrAC 91, 53-66 (2017). https:// doi.org/10.1016/j.trac.2017.04.003

81. T.T. Tung, M.J. Nine, M. Krebsz, T. Pasinszki, C.J. Coghlan, D.N.H. Tran, D. Losic, Recent advances in sensing applications of graphene assemblies and their composites. Adv. Funct. Mater. 27, 1-57 (2017). https://doi. org/10.1002/adfm.201702891

82. A. Nag, A. Mitra, S.C. Mukhopadhyay, Graphene and its sensor-based applications: a review. Sensors Actuat. A Phys. 270, 177-194 (2018). https://doi.org/10.1016/j.sna.2017.12.028

83. L. Wang, A. Wu, G. Wei, Graphene-based aptasensors: from moleculeinterface interactions to sensor design and biomedical diagnostics. Analyst. 143, 1526-1543 (2018). https://doi.org/10.1039/c8an00081f

84. D.P. Singh, C.E. Herrera, B. Singh, S. Singh, R.K. Singh, R. Kumar, Graphene oxide: an efficient material and recent approach for biotechnological and biomedical applications. Mater. Sci. Eng. C 86, 173-197 (2018). https://doi.org/10.1016/j.msec.2018.01.004

85. S. Taniselass, M.K.M. Arshad, S.C.B. Gopinath, Graphene-based electrochemical biosensors for monitoring noncommunicable disease biomarkers. Biosens. Bioelectron. 130, 276-292 (2019). https://doi. org/10.1016/j.bios.2019.01.047

86. W. Wang, H. Su, Y. Wu, T. Zhou, T. Li, Review-biosensing and biomedical applications of graphene: a review of current progress and future prospect. J. Electrochem. Soc. 166, B505-B520 (2019). https://doi. org/10.1149/2.1231906jes

87. C. Nie, L. Ma, S. Li, X. Fan, Y. Yang, C. Cheng, W. Zhao, C. Zhao, Recent progresses in graphene based bio-functional nanostructures for advanced biological and cellular interfaces. Nano Today. 26, 57-97 (2019). https://doi.org/10.1016/..nantod.2019.03.003

88. G. Reina, J.M. González-Domínguez, A. Criado, E. Vázquez, A. Bianco, M. Prato, Promises, facts and challenges for graphene in biomedical applications. Chem. Soc. Rev. 46, 4400-4416 (2017). https://doi.org/10.1039/ c7cs00363c

89. C.S. Park, H. Yoon, O.S. Kwon, Graphene-based nanoelectronic biosensors. J. Ind. Eng. Chem. 38, 13-22 (2016)

90. S. Haar, A. Ciesielski, J. Clough, H. Yang, R. Mazzaro, F. Richard, S. Conti, N. Merstorf, M. Cecchini, V. Morandi, A supramolecular strategy to leverage the liquid-phase exfoliation of graphene in the presence of surfactants: unraveling the role of the length of fatty acids. Small 11, 1691-1702 (2015)

91. H. Choi, K. Ahn, Y. Lee, S. Noh, H. Yoon, Free-standing, multilayered graphene/polyaniline-glue/graphene nanostructures for flexible, solidstate electrochemical capacitor application. Adv. Mater. Interfaces. 2, $1500117(2015)$

92. Y. Xu, H. Bai, G. Lu, C. Li, G. Shi, Flexible graphene films via the filtration of water-soluble noncovalent functionalized graphene sheets. J. Am. Chem. Soc. 130, 5856-5857 (2008)

93. C.K. Chua, M. Pumera, Chemical reduction of graphene oxide: a synthetic chemistry viewpoint. Chem. Soc. Rev. 43, 291-312 (2014)

94. K.S. Novoselov, V.I. Fal, L. Colombo, P.R. Gellert, M.G. Schwab, K. Kim, A roadmap for graphene. Nature 490, 192 (2012)

95. A. Vasilescu, A. Hayat, S. Gáspár, J.L. Marty, Advantages of carbon nanomaterials in electrochemical aptasensors for food analysis. Electroanalysis 30, 2-19 (2018). https://doi.org/10.1002/elan.201700578

96. M. Pumera, Graphene-based nanomaterials and their electrochemistry. Chem. Soc. Rev. 39, 4146-4157 (2010)

97. A. Ambrosi, C.K. Chua, A. Bonanni, M. Pumera, Electrochemistry of graphene and related materials. Chem. Rev. 114, 7150-7188 (2014)

98. M. Pumera, Electrochemistry of graphene: new horizons for sensing and energy storage. Chem. Rec. 9, 211-223 (2009)

99. M. Pumera, Electrochemistry of graphene, graphene oxide and other graphenoids. Electrochem. Commun. 36, 14-18 (2013)

100. A. Kaplan, Z. Yuan, J.D. Benck, A. Govind Rajan, X.S. Chu, Q.H. Wang, M.S. Strano, Current and future directions in electron transfer chemistry 
of graphene. Chem. Soc. Rev. 46, 4530-4571 (2017). https://doi. org/10.1039/c7cs00181a

101. X. Wang, D. Gao, M. Li, H. Li, C. Li, X. Wu, B. Yang, CVD graphene as an electrochemical sensing platform for simultaneous detection of biomolecules. Sci. Rep. 7, 1-9 (2017). https://doi.org/10.1038/s4159 8-017-07646-2

102. T. Zhang, J. Liu, C. Wang, X. Leng, Y. Xiao, L. Fu, Synthesis of graphene and related two-dimensional materials for bioelectronics devices. Biosens. Bioelectron. 89, 28-42 (2017)

103. M. Sprinkle, M. Ruan, Y. Hu, J. Hankinson, M. Rubio-Roy, B. Zhang, X. Wu, C. Berger, W.A. De Heer, Scalable templated growth of graphene nanoribbons on SiC. Nat. Nanotechnol. 5, 727 (2010)

104. D.H. Lee, J.E. Kim, T.H. Han, J.W. Hwang, S. Jeon, S. Choi, S.H. Hong, W.J. Lee, R.S. Ruoff, S.O. Kim, Versatile carbon hybrid films composed of vertical carbon nanotubes grown on mechanically compliant graphene films. Adv. Mater. 22, 1247-1252 (2010)

105. X. Li, W. Cai, J. An, S. Kim, J. Nah, D. Yang, R. Piner, A. Velamakanni, I. Jung, E. Tutuc, Large-area synthesis of high-quality and uniform graphene films on copper foils. Science (80-) 324, 1312-1314 (2009)

106. Y.I. Zhang, L. Zhang, C. Zhou, Review of chemical vapor deposition of graphene and related applications. Acc. Chem. Res. 46, 2329-2339 (2013)

107. I. Pasternak, M. Wesolowski, I. Jozwik, M. Lukosius, G. Lupina, P. Dabrowski, J.M. Baranowski, W. Strupinski, Graphene growth on Ge (100)/Si (100) substrates by CVD method. Sci. Rep. 6, 21773 (2016)

108. J. Dabrowski, G. Lippert, J. Avila, J. Baringhaus, I. Colambo, Y.S. Dedkov, F. Herziger, G. Lupina, J. Maultzsch, T. Schaffus, Understanding the growth mechanism of graphene on Ge/Si (001) surfaces. Sci. Rep. 6, 31639 (2016)

109. L. Baraton, Z.B. He, C.S. Lee, C.S. Cojocaru, M. Châtelet, J.-L. Maurice, Y.H. Lee, D. Pribat, On the mechanisms of precipitation of graphene on nickel thin films. EPL. 96, 46003 (2011)

110. M. Losurdo, M.M. Giangregorio, P. Capezzuto, G. Bruno, Graphene CVD growth on copper and nickel: role of hydrogen in kinetics and structure. Phys. Chem. Chem. Phys. 13, 20836-20843 (2011)

111. J. Zhang, Z. Wang, T. Niu, S. Wang, Z. Li, W. Chen, Elementary process for CVD graphene on Cu (110): size-selective carbon clusters. Sci. Rep. 4, $4431(2014)$

112. T. Niu, M. Zhou, J. Zhang, Y. Feng, W. Chen, Growth intermediates for CVD graphene on $\mathrm{Cu}$ (111): carbon clusters and defective graphene. J. Am. Chem. Soc. 135, 8409-8414 (2013)

113. M. Liu, Y. Gao, Y. Zhang, Y. Zhang, D. Ma, Q. Ji, T. Gao, Y. Chen, Z. Liu, Single and polycrystalline graphene on Rh (111) following different growth mechanisms. Small 9, 1360-1366 (2013)

114. A. Kordatos, N. Kelaidis, S.A. Giamini, J. Marquez-Velasco, E. Xenogiannopoulou, P. Tsipas, G. Kordas, A. Dimoulas, AB stacked few layer graphene growth by chemical vapor deposition on single crystal Rh (1 111 ) and electronic structure characterization. Appl. Surf. Sci. 369, 251-256 (2016)

115. S. Yang, M.R. Lohe, K. Müllen, X. Feng, New-generation graphene from electrochemical approaches: production and applications. Adv. Mater. 28, 6213-6221 (2016)

116. F. Li, H. Peng, D. Xia, J. Yang, K. Yang, F. Yin, W. Yuan, Highly sensitive, selective, and flexible $\mathrm{NO}_{2}$ chemiresistors based on multilevel structured three-dimensional reduced graphene oxide fiber scaffold modified with aminoanthroquinone moieties and Ag nanoparticles. ACS Appl. Mater. Interfaces. 11, 9309-9316 (2019). https://doi.org/10.1021/ acsami.8b20462

117. J. Kim, L.J. Cote, F. Kim, W. Yuan, K.R. Shull, J. Huang, Graphene oxide sheets at interfaces. J. Am. Chem. Soc. 132, 8180-8186 (2010)

118. C. Cheng, S. Li, A. Thomas, N.A. Kotov, R. Haag, Functional graphene nanomaterials based architectures: biointeractions, fabrications, and emerging biological applications. Chem. Rev. 117, 1826-1914 (2017). https://doi.org/10.1021/acs.chemrev.6b00520

119. M. Bacon, S.J. Bradley, T. Nann, Graphene quantum dots. Part. Part. Syst. Charact. 31, 415-428 (2014)

120. N. Suzuki, Y. Wang, P. Elvati, Z.-B. Qu, K. Kim, S. Jiang, E. Baumeister, J. Lee, B. Yeom, J.H. Bahng, Chiral graphene quantum dots. ACS Nano 10, 1744-1755 (2016)
121. Y. Chong, Y. Ma, H. Shen, X. Tu, X. Zhou, J. Xu, J. Dai, S. Fan, Z. Zhang, The in vitro and in vivo toxicity of graphene quantum dots. Biomaterials 35 5041-5048 (2014)

122. Q. Ye, L. Guo, D. Wu, B. Yang, Y. Tao, L. Deng, Y. Kong, Covalent functionalization of bovine serum albumin with graphene quantum dots for stereospecific molecular recognition. Anal. Chem. 91, 11864-11871 (2019). https://doi.org/10.1021/acs.analchem.9b02605

123. C. Cleeton, A. Keirouz, X. Chen, N. Radacsi, Electrospun nanofibers for drug delivery and biosensing. ACS Biomater. Sci. Eng. 5, 4183-4205 (2019). https://doi.org/10.1021/acsbiomaterials.9b00853

124. Y. Ding, W. Li, F. Zhang, Z. Liu, N. ZanjanizadehEzazi, D. Liu, H.A. Santos, Electrospun fibrous architectures for drug delivery, tissue engineering and cancer therapy. Adv. Funct. Mater. 29, 1-35 (2019). https://doi. org/10.1002/adfm.201802852

125. S. Jian, J. Zhu, S. Jiang, S. Chen, H. Fang, Y. Song, G. Duan, Y. Zhang, H. Hou, Nanofibers with diameter below one nanometer from electrospinningt. RSC Adv. 8, 4794-4802 (2018). https://doi.org/10.1039/c7ra1 3444d

126. C.T. Kenry, Lim, nanofiber technology: current status and emerging developments. Prog. Polym. Sci. 70, 1-17 (2017). https://doi. org/10.1016/j.progpolymsci.2017.03.002

127. N. Aliheidari, N. Aliahmad, M. Agarwal, H. Dalir, Electrospun nanofibers for label-free sensor applications. Sensors. 19, 3587 (2019). https://doi. org/10.3390/s19163587

128. A. Aydogdu, G. Sumnu, S. Sahin, A novel electrospun hydroxypropyl methylcellulose/polyethylene oxide blend nanofibers: morphology and physicochemical properties. Carbohydr. Polym. 181, 234-246 (2018). https://doi.org/10.1016/j.carbpol.2017.10.071

129. A. Nathani, C.S. Sharma, Electrospun mesoporous poly(styrene-blockmethylmethacrylate) nanofibers as biosensing platform: effect of fibers porosity on sensitivity. Electroanalysis. 1, 8 (2019). https://doi. org/10.1002/elan.201800796

130. D. Silvestri, J. Mikšičček, S. Wacławek, R. Torres-Mendieta, V.V.T. Padil, M. Černík, Production of electrospun nanofibers based on graphene oxide/gum Arabic. Int. J. Biol. Macromol. 124, 396-402 (2019). https:// doi.org/10.1016/j.jibiomac.2018.11.243

131. R. Zhao, X. Lu, C. Wang, Electrospinning based all-nano composite materials: recent achievements and perspectives. Compos. Commun. 10, 140-150 (2018). https://doi.org/10.1016/j.coco.2018.09.005

132. M. Zhang, X. Zhao, G. Zhang, G. Wei, Z. Su, Electrospinning design of functional nanostructures for biosensor applications. J. Mater. Chem. B. 5, 1699-1711 (2017). https://doi.org/10.1039/c6tb03121h

133. H.J. Salavagione, M.A. Gómez-Fatou, P.S. Shuttleworth, G.J. Ellis, New perspectives on graphene/polymer fibers and fabrics for smart textiles: the relevance of the polymer/graphene interphase. Front. Mater. 5, 1-6 (2018). https://doi.org/10.3389/fmats.2018.00018

134. Q. Wu, Y. Xu, Z. Yao, A. Liu, G. Shi, Supercapacitors based on flexible graphene/polyaniline nanofiber composite films. ACS Nano 4, 1963-1970 (2010)

135. N.A. Kumar, H.-J. Choi, Y.R. Shin, D.W. Chang, L. Dai, J.-B. Baek, Polyaniline-grafted reduced graphene oxide for efficient electrochemical supercapacitors. ACS Nano 6, 1715-1723 (2012)

136. Y. Si, E.T. Samulski, Synthesis of water soluble graphene. Nano Lett. 8 1679-1682 (2008)

137. Q. Wu, Y. Sun, H. Bai, G. Shi, High-performance supercapacitor electrodes based on graphene hydrogels modified with 2-aminoanthraquinone moieties. Phys. Chem. Chem. Phys. 13, 11193-11198 (2011)

138. D. Cai, M. Song, Recent advance in functionalized graphene/polymer nanocomposites. J. Mater. Chem. 20, 7906-7915 (2010)

139. T. Ramanathan, A.A. Abdala, S. Stankovich, D.A. Dikin, M. Herrera-Alonso, R.D. Piner, D.H. Adamson, H.C. Schniepp, X. Chen, R.S. Ruoff, Functionalized graphene sheets for polymer nanocomposites. Nat. Nanotechnol. 3, $327(2008)$

140. H. Li, W. Shi, X. Zeng, S. Huang, H. Zhang, X. Qin, Improved desalination properties of hydrophobic GO-incorporated PVDF electrospun nanofibrous composites for vacuum membrane distillation. Sep. Purif. Technol. 230, 115889 (2020). https://doi.org/10.1016/j.seppur.2019.115889

141. F. Du, L. Sun, Z. Huang, Z. Chen, Z. Xu, G. Ruan, C. Zhao, Electrospun reduced graphene oxide/TiO2/poly(acrylonitrile-co-maleic acid) composite nanofibers for efficient adsorption and photocatalytic removal of 
malachite green and leucomalachite green. Chemosphere 239, 124764 (2020). https://doi.org/10.1016/j.chemosphere.2019.124764

142. X. Gu, Y. Li, R. Cao, S. Liu, C. Fu, S. Feng, C. Yang, W. Cheng, Y. Wang, Novel electrospun poly(lactic acid)/poly(butylene carbonate)/graphene oxide nanofiber membranes for antibacterial applications. AIP Adv. (2019). https://doi.org/10.1063/1.5100109

143. S. Parandeh, M. Kharaziha, F. Karimzadeh, An eco-friendly triboelectric hybrid nanogenerators based on graphene oxide incorporated polycaprolactone fibers and cellulose paper. Nano Energy. 59, 412-421 (2019). https://doi.org/10.1016/j.nanoen.2019.02.058

144. H. Stone, S. Lin, K. Mequanint, Preparation and characterization of electrospun rGO-poly(ester amide) conductive scaffolds. Mater. Sci. Eng. C 98, 324-332 (2019). https://doi.org/10.1016/j.msec.2018.12.122

145. S. Bahrami, A. Solouk, H. Mirzadeh, A.M. Seifalian, Electroconductive polyurethane/graphene nanocomposite for biomedical applications. Compos. Part B Eng. 168, 421-431 (2019). https://doi.org/10.1016/j. compositesb.2019.03.044

146. G. Ghaderi, H. Tavanai, M. Bazarganipour, Electrospun graphene oxide incorporated PAN nanofibers, before and after activation. Mater. Res. Express. 6, 105047 (2019)

147. E. Maccaferri, L. Mazzocchetti, T. Benelli, A. Zucchelli, L. Giorgini, Morphology, thermal, mechanical properties and ageing of nylon 6,6/ graphene nanofibers as Nano2 materials. Compos. Part B Eng. 166, 120-129 (2019). https://doi.org/10.1016/..compositesb.2018.11.096

148. D.A. Samani, A. Doostmohammadi, M.R. Nilforoushan, H. Nazari, Electrospun polycaprolactone/graphene/baghdadite composite nanofibres with improved mechanical and biological properties. Fibers Polym. 20 982-990 (2019). https://doi.org/10.1007/s12221-019-1161-5

149. S. Pan, Z. Qi, Q. Li, Y. Ma, C. Fu, S. Zheng, W. Kong, Q. Liu, X. Yang, Graphene oxide-PLGA hybrid nanofibres for the local delivery of IGF-1 and BDNF in spinal cord repair. Artif. Cells Nanomed. Biotechnol. 47, 651-664 (2019). https://doi.org/10.1080/21691401.2019.1575843

150. S.N. Banitaba, D. Semnani, E. Heydari-Soureshjani, B. Rezaei, A.A. Ensafi, Nanofibrous poly(ethylene oxide)-based structures incorporated with multi-walled carbon nanotube and graphene oxide as all-solid-state electrolytes for lithium ion batteries. Polym. Int. (2019). https://doi. org/10.1002/pi.5889

151. M. Jahan Biglari, R. Semnani Rahbar, M. Shabanian, H.A. Khonakdar, Novel composite nanofibers based on polyamide 66/graphene oxidegrafted aliphatic- aromatic polyamide: preparation and characterization. Polym. Plast. Technol. Eng. (2018). https://doi.org/10.1080/03602 559.2018 .1542712

152. J. Ren, Y.C. Woo, M. Yao, S. Lim, L.D. Tijing, H.K. Shon, Nanoscale zerovalent iron (nZVI) immobilization onto graphene oxide (GO)-incorporated electrospun polyvinylidene fluoride (PVDF) nanofiber membrane for groundwater remediation via gravity-driven membrane filtration. Sci. Total Environ. 688, 787-796 (2019). https://doi.org/10.1016/j.scito tenv.2019.05.393

153. Y.I. Choi, B.U. Hwang, M. Meeseepong, A. Hanif, S. Ramasundaram, T.Q. Trung, N.E. Lee, Stretchable and transparent nanofiber-networked electrodes based on nanocomposites of polyurethane/reduced graphene oxide/silver nanoparticles with high dispersion and fused junctions. Nanoscale. 11, 4015-4024 (2019). https://doi.org/10.1039/c8nr10170a

154. R. Weng, L. Sun, L. Jiang, N. Li, G. Ruan, J. Li, F. Du, Electrospun graphene oxide-doped nanofiber-based solid phase extraction followed by high-performance liquid chromatography for the determination of tetracycline antibiotic residues in food samples. Food Anal. Methods 12, 1594-1603 (2019). https://doi.org/10.1007/s12161-019-01495-7

155. C.L. Huang, H.H. Wu, Y.C. Jeng, W.Z. Liang, Electrospun graphene nanosheet-filled poly(trimethylene terephthalate) composite fibers: Effects of the graphene nanosheet content on morphologies, electrical conductivity, crystallization behavior, and mechanical properties. Polymers (2019). https://doi.org/10.3390/polym11010164

156. N.M. Aboamera, A. Mohamed, A. Salama, T.A. Osman, A. Khattab, An effective removal of organic dyes using surface functionalized cellulose acetate/graphene oxide composite nanofibers. Cellulose $\mathbf{2 5}$, 4155-4166 (2018). https://doi.org/10.1007/s10570-018-1870-8

157. A.H. Davoodi, S. Mazinani, F. Sharif, S.O. Ranaei-Siadat, GO nanosheets localization by morphological study on PLA-GO electrospun nanocomposite nanofibers. J. Polym. Res. 25, 16-19 (2018). https://doi. org/10.1007/s10965-018-1589-0
158. K. Ruan, Y. Guo, Y. Tang, Y. Zhang, J. Zhang, M. He, J. Kong, J. Gu, Improved thermal conductivities in polystyrene nanocomposites by incorporating thermal reduced graphene oxide via electrospinninghot press technique. Compos. Commun. 10, 68-72 (2018). https://doi. org/10.1016/j.coco.2018.07.003

159. V. Ruiz, A. Pérez-Marquez, J. Maudes, H.J. Grande, N. Murillo, Enhanced photostability and sensing performance of graphene quantum dots encapsulated in electrospun polyacrylonitrile nanofibrous filtering membranes. Sensors Actuators B Chem. 262, 902-912 (2018). https:// doi.org/10.1016/j.snb.2018.02.081

160. K. Javed, A. Krumme, M. Viirsalu, I. Krasnou, T. Plamus, V. Vassiljeva, E. Tarasova, N. Savest, A. Mere, V. Mikli, M. Danilson, T. Kaljuvee, S. Lange, Q. Yuan, P.D. Topham, C.M. Chen, A method for producing conductive graphene biopolymer nanofibrous fabrics by exploitation of an ionic liquid dispersant in electrospinning. Carbon N. Y. 140, 148-156 (2018). https://doi.org/10.1016/i.carbon.2018.08.034

161. A. Gebrekrstos, G. Madras, S. Bose, Piezoelectric response in electrospun poly(vinylidene fluoride) fibers containing fluoro-doped graphene derivatives. ACS Omega. 3, 5317-5326 (2018). https://doi.org/10.1021/ acsomega.8b00237

162. A. Pavinatto, L.A. Mercante, M.H.M. Facure, R.B. Pena, R.C. Sanfelice, L.H.C. Mattoso, D.S. Correa, Ultrasensitive biosensor based on polyvinylpyrrolidone/chitosan/reduced graphene oxide electrospun nanofibers for $17 a$ - Ethinylestradiol electrochemical detection. Appl. Surf. Sci. 458, 431-437 (2018). https://doi.org/10.1016/j.apsusc.2018.07.035

163. H. Abdali, A. Ajji, Preparation of electrospun nanocomposite nanofibers of polyaniline/poly (methyl methacrylate) with amino-functionalized graphene. Polymers (Basel). 9, 453 (2017). https://doi.org/10.3390/ polym9090453

164. X. Wang, Y. Gao, X. Li, Y. Xu, J. Jiang, J. Hou, Q. Li, L.S. Turng, Selective localization of graphene oxide in electrospun polylactic acid/poly( $\varepsilon$ caprolactone) blended nanofibers. Polym. Test. 59, 396-403 (2017). https://doi.org/10.1016/j.polymertesting.2017.02.022

165. M.M. Abolhasani, K. Shirvanimoghaddam, M. Naebe, PVDF/graphene composite nanofibers with enhanced piezoelectric performance for development of robust nanogenerators. Compos. Sci. Technol. 138, 49-56 (2017). https://doi.org/10.1016/j.compscitech.2016.11.017

166. M. Heidari, H. Bahrami, M. Ranjbar-Mohammadi, Fabrication, optimization and characterization of electrospun poly(caprolactone)/gelatin/ graphene nanofibrous mats. Mater. Sci. Eng. C 78, 218-229 (2017). https ://doi.org/10.1016/j.msec.2017.04.095

167. M. Abbasipour, R. Khajavi, A.A. Yousefi, M.E. Yazdanshenas, F. Razaghian, The piezoelectric response of electrospun PVDF nanofibers with graphene oxide, graphene, and halloysite nanofillers: a comparative study. J. Mater. Sci.: Mater. Electron. 28, 15942-15952 (2017). https://doi. org/10.1007/s10854-017-7491-4

168. P. Sahatiya, S. Badhulika, One-step in situ synthesis of single aligned graphene-ZnO nanofiber for UV sensing. RSC Adv. 5, 82481-82487 (2015). https://doi.org/10.1039/c5ra15351d

169. J. He, M. Zhou, L. Wang, S. Zhao, Q. Wang, B. Ding, S. Cui, Electrospinning in situ synthesis of graphene-doped porous copper indium disulfide/ carbon composite nanofibers for highly efficient counter electrode in dye-sensitized solar cells. Electrochim. Acta 215, 626-636 (2016)

170. Y.-L. Huang, A. Baji, H.-W. Tien, Y.-K. Yang, S.-Y. Yang, C.-C.M. Ma, H.-Y. Liu, Y.-W. Mai, N.-H. Wang, Self-assembly of graphene onto electrospun polyamide 66 nanofibers as transparent conductive thin films. Nanotechnology. 22, 475603 (2011)

171. M.V. Jose, B.W. Steinert, V. Thomas, D.R. Dean, M.A. Abdalla, G. Price, G.M. Janowski, Morphology and mechanical properties of Nylon 6/MWNT nanofibers. Polymer (Guildf). 48, 1096-1104 (2007)

172. L.E. Jasso-Ramos, A. Ojeda-Hernández, C. Guerrero-Bermea, N.A. GarciaGómez, J. Manriquez, S. Sepulveda-Guzmán, R. Cruz-Silva, Simultaneous intercalated assembly of mesostructured hybrid carbon nanofiber/ reduced graphene oxide and its use in electrochemical sensing. Nanotechnology. (2019). https://doi.org/10.1088/1361-6528/aae879

173. C. Shan, Y. Wang, S. Xie, H. Guan, M. Argueta, Y. Yue, Free-standing nitrogen-doped graphene-carbon nanofiber composite mats: electrospinning synthesis and application as anode material for lithium-ion batteries. J. Chem. Technol. Biotechnol. (2019). https://doi.org/10.1002/ jctb.6114 
174. X.-Y. Wang, A. Narita, K. Müllen, Precision synthesis versus bulk-scale fabrication of graphenes. Nat. Rev. Chem. 2, 1-10 (2017). https://doi. org/10.1038/s41570-017-0100

175. Z.Q. Feng, F. Wu, L. Jin, T. Wang, W. Dong, J. Zheng, Graphene nanofibrous foam designed as an efficient oil absorbent. Ind. Eng. Chem. Res. 58, 3000-3008 (2019). https://doi.org/10.1021/acs.iecr.8b05646

176. M. Soikkeli, K. Kurppa, M. Kainlauri, S. Arpiainen, A. Paananen, D. Gunnarsson, J.J. Joensuu, P. Laaksonen, M. Prunnila, M.B. Linder, Graphene biosensor programming with genetically engineered fusion protein monolayers. ACS Appl. Mater. Interfaces. 8, 8257-8264 (2016)

177. P. Zhang, Y. Huang, X. Lu, S. Zhang, J. Li, G. Wei, Z. Su, One-step synthesis of large-scale graphene film doped with gold nanoparticles at liquidair interface for electrochemistry and Raman detection applications. Langmuir 30, 8980-8989 (2014)

178. V. Beachley, X. Wen, Polymer nanofibrous structures: fabrication, biofunctionalization, and cell interactions. Prog. Polym. Sci. 35, 868-892 (2010)

179. H.S. Koh, T. Yong, C.K. Chan, S. Ramakrishna, Enhancement of neurite outgrowth using nano-structured scaffolds coupled with laminin. Biomaterials 29, 3574-3582 (2008)

180. C. Liu, G. Shi, G. Wang, P. Mishra, S. Jia, X. Jiang, P. Zhang, Y. Dong, Z. Wang, Preparation and electrochemical studies of electrospun phosphorus doped porous carbon nanofibers. RSC Adv. 9, 6898-6906 (2019). https://doi.org/10.1039/c8ra10193k

181. C.S. Reddy, G. Murali, A.S. Reddy, S. Park, I. In, GO incorporated SnO2 nanotubes as fast response sensors for ethanol vapor in different atmospheres. J. Alloys Compd. 813, 152251 (2019). https://doi. org/10.1016/j.jallcom.2019.152251

182. N. Tambakoozadeh, M. Youssefi, D. Semnani, A composite polyaniline/ graphene-coated polyamide6 nanofiber mat for electrochemical applications. Polym. Adv. Technol. (2019). https://doi.org/10.1002/pat.4714

183. N. Zheng, Y. Song, L. Wang, J. Gao, Y. Wang, X. Dong, Improved electrical and mechanical properties for the reduced graphene oxide-decorated polymer nanofiber composite with a core-shell structure. Ind. Eng. Chem. Res. 58, 15470-15478 (2019). https://doi.org/10.1021/acs. iecr.9b01766

184. M. Gozutok, V. Sadhu, H.T. Sasmazel, Development of poly(vinyl alcohol) (PVA)/reduced graphene oxide ( $\mathrm{rGO}$ ) electrospun mats. J. Nanosci. Nanotechnol. 19, 4292-4298 (2019). https://doi.org/10.1166/ jnn.2019.16290

185. H. Nazari, S. Azadi, S. Hatamie, M.S. Zomorrod, K. Ashtari, M. Soleimani, S. Hosseinzadeh, Fabrication of graphene-silver/polyurethane nanofibrous scaffolds for cardiac tissue engineering. Polym. Adv. Technol. 30 2086-2099 (2019). https://doi.org/10.1002/pat.4641

186. M. Ionita, A.M. Pandele, L. Crica, L. Pilan, Improving the thermal and mechanical properties of polysulfone by incorporation of graphene oxide. Compos. Part B Eng. 59, 133-139 (2014)

187. R. Rezaee, S. Nasseri, A.H. Mahvi, R. Nabizadeh, S.A. Mousavi, A. Rashidi, A. Jafari, S. Nazmara, Fabrication and characterization of a polysulfonegraphene oxide nanocomposite membrane for arsenate rejection from water. J. Environ. Heal. Sci. Eng. 13, 61 (2015)

188. M. Yoonessi, Y. Shi, D.A. Scheiman, M. Lebron-Colon, D.M. Tigelaar, R.A. Weiss, M.A. Meador, Graphene polyimide nanocomposites; thermal, mechanical, and high-temperature shape memory effects. ACS Nano 6, 7644-7655 (2012)

189. I. Tseng, J. Chang, S. Huang, M. Tsai, Enhanced thermal conductivity and dimensional stability of flexible polyimide nanocomposite film by addition of functionalized graphene oxide. Polym. Int. 62, 827-835 (2013)

190. M. Yoonessi, J.R. Gaier, Highly conductive multifunctional graphene polycarbonate nanocomposites. ACS Nano 4, 7211-7220 (2010)

191. G. Gedler, M. Antunes, V. Realinho, J.I. Velasco, Thermal stability of polycarbonate-graphene nanocomposite foams. Polym. Degrad. Stab. 97, 1297-1304 (2012)

192. D. Zheng, G. Tang, H.-B. Zhang, Z.-Z. Yu, F. Yavari, N. Koratkar, S.-H. Lim, M.W. Lee, In situ thermal reduction of graphene oxide for high electrical conductivity and low percolation threshold in polyamide 6 nanocomposites. Compos. Sci. Technol. 72, 284-289 (2012)

193. H. Liu, L. Hou, W. Peng, Q. Zhang, X. Zhang, Fabrication and characterization of polyamide 6-functionalized graphene nanocomposite fiber. J. Mater. Sci. 47, 8052-8060 (2012)

194. J. Bian, H.L. Lin, F.X. He, L. Wang, X.W. Wei, I.-T. Chang, E. Sancaktar, Processing and assessment of high-performance poly (butylene terephthalate) nanocomposites reinforced with microwave exfoliated graphite oxide nanosheets. Eur. Polym. J. 49, 1406-1423 (2013)

195. H. Chen, C. Huang, W. Yu, C. Zhou, Effect of thermally reduced graphite oxide ( $\operatorname{TrGO}$ ) on the polymerization kinetics of poly (butylene terephthalate)(pCBT)/TrGO nanocomposites prepared by in situ ring-opening polymerization of cyclic butylene terephthalate. Polymer (Guildf). 54, 1603-1611 (2013)

196. M. Gorji, A. Sadeghianmaryan, H. Rajabinejad, S. Nasherolahkam, X. Chen, Development of highly $\mathrm{pH}$-sensitive hybrid membranes by simultaneous electrospinning of amphiphilic nanofibers reinforced with graphene oxide. J. Funct. Biomater. (2019). https://doi.org/10.3390/ jfb10020023

197. H. Nosrati, R.S. Mamoory, F. Dabir, D.Q.S. Le, C.E. Bünger, M.C. Perez, M.A. Rodriguez, Effects of hydrothermal pressure on in situ synthesis of 3D graphene-hydroxyapatite nano structured powders. Ceram. Int. 45 1761-1769 (2019)

198. C. Zhang, F. Zhao, Y. He, Y. She, S. Hong, J. Ma, M. Wang, Z. Cao, T. Li, A.M.A. El-Aty, J. Ping, Y. Ying, J. Wang, A disposable electrochemical sensor based on electrospinning of molecularly imprinted nanohybrid films for highly sensitive determination of the organotin acaricide cyhexatin. Microchim. Acta. (2019). https://doi.org/10.1007/s0060 4-019-3631-2

199. A. Macagnano, E. Zampetti, E. Kny, Electrospinning for high performance sensors (Springer, Berlin, 2015)

200. S. Agarwal, A. Greiner, J.H. Wendorff, Functional materials by electrospinning of polymers. Prog. Polym. Sci. 38, 963-991 (2013). https://doi. org/10.1016/j.progpolymsci.2013.02.001

201. C.L. Zhang, S.H. Yu, Nanoparticles meet electrospinning: recent advances and future prospects. Chem. Soc. Rev. 43, 4423-4448 (2014). https://doi.org/10.1039/c3cs60426h

202. P. Zhang, X. Zhao, Y. Ji, Z. Ouyang, X. Wen, J. Li, Z. Su, G. Wei, Electrospinning graphene quantum dots into a nanofibrous membrane for dualpurpose fluorescent and electrochemical biosensors. J. Mater. Chem. B. 3, 2487-2496 (2015). https://doi.org/10.1039/c4tb02092h

203. T.S. Cabral, L.F. Sgobbi, J. Delezuk, R.S. Pessoa, A.O. Lobo, B.V.M. Rodrigues, Glucose sensing via a green and low-cost platform from electrospun poly (vinyl alcohol)/graphene quantum dots fibers. Mater. Today Proc. 14,694-699 (2019). https://doi.org/10.1016/j.matpr.2019.02.008

204. H. Karimiyan, A. Uheida, M. Hadjmohammadi, M.M. Moein, M. AbdelRehim, Polyacrylonitrile/graphene oxide nanofibers for packed sorbent microextraction of drugs and their metabolites from human plasma samples. Talanta 201,474-479 (2019). https://doi.org/10.1016/j.talan ta.2019.04.027

205. H. Li, W. Zhang, Q. Ding, X. Jin, Q. Ke, Z. Li, D. Wang, C. Huang, Facile strategy for fabrication of flexible, breathable, and washable piezoelectric sensors via welding of nanofibers with multiwalled carbon nanotubes (MWCNTs). ACS Appl. Mater. Interfaces. (2019). https://doi. org/10.1021/acsami.9b10886

206. H. Ren, L. Zheng, G. Wang, X. Gao, Z. Tan, J. Shan, L. Cui, K. Li, M. Jian, L. Zhu, Y. Zhang, H. Peng, D. Wei, Z. Liu, Transfer-medium-free nanofiberreinforced graphene film and applications in wearable transparent pressure sensors. ACS Nano 13, 5541-5548 (2019). https://doi. org/10.1021/acsnano.9b00395

\section{Publisher's Note}

Springer Nature remains neutral with regard to jurisdictional claims in published maps and institutional affiliations. 